\title{
Managing information asymmetry in public-private relationships undergoing a digital transformation: the role of contractual and relational governance
}

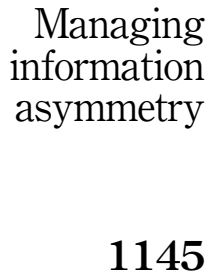

Received 30 September 2020 Revised 18 March 2021 12 May 2021

Accepted 8 June 2021

\author{
Tom A.E. Aben and Wendy van der Valk \\ Department of Management, Tilburg School of Economics and Management, \\ Tilburg University, Tilburg, The Netherlands \\ Jens K. Roehrich \\ HPC Supply Chain Innovation Lab, \\ Information, Decisions and Operations (IDO) Division, School of Management, \\ University of Bath, Bath, UK, and \\ Kostas Selviaridis \\ Department of Management Science, Lancaster University Management School, \\ Bailrigg, UK
}

\begin{abstract}
Purpose - Inter-organisational governance is an important enabler for information processing, particularly in relationships undergoing digital transformation (DT) where partners depend on each other for information in decision-making. Based on information processing theory (IPT), the authors theoretically and empirically investigate how governance mechanisms address information asymmetry (uncertainty and equivocality) arising in capturing, sharing and interpreting information generated by digital technologies.

Design/methodology/approach - IPT is applied to four cases of public-private relationships in the Dutch infrastructure sector that aim to enhance the quantity and quality of information-based decision-making by implementing digital technologies. The investigated relationships are characterised by differing degrees and
\end{abstract}

(C) Tom A.E. Aben, Wendy van der Valk, Jens K. Roehrich and Kostas Selviaridis. Published by Emerald Publishing Limited. This article is published under the Creative Commons Attribution (CC BY 4.0) licence. Anyone may reproduce, distribute, translate and create derivative works of this article (for both commercial and non-commercial purposes), subject to full attribution to the original publication and authors. The full terms of this licence may be seen at http://creativecommons.org/licences/by/4.0/ legalcode

The authors express their gratitude to the research assistants Christina Föll and Sophie Strijk, who both assisted with analysing and coding the data for both the Rail cases, and to graduate students Megan Ridderhof and Joep van de Water, who - together with the lead author - conducted interviews for the Rail A and Road A cases, respectively. The authors also acknowledge the support of Henk Akkermans, Brenda Espinosa and Saskia Lavrijssen, fellow researchers in the LONGA VIA research project, in developing the study and getting access to the case organisations and during the writing process. Finally, the authors thank all the participants of WION 2020 for their valuable feedback on an earlier version of the paper.

This study was supported by the Dutch Research Council (NWO; grant number 439-16-807) and co-financed by Next Generation Infrastructures (NGinfra).

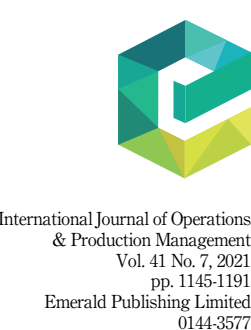

DOI 10.1108/JJOPM-09-2020-357 
IJOPM

41,7 types of information uncertainty and equivocality. The authors build on rich data sets including archival data, observations, contract documents and interviews.

Findings - Addressing information uncertainty requires invoking contractual control and coordination. Contract clauses should be precise and incentive schemes functional in terms of information requirements. Information equivocality is best addressed by using relational governance. Identifying information requirements and reducing information uncertainty are a prerequisite for the transformation activities that organisations perform to reduce information equivocality.

Practical implications - The study offers insights into the roles of both governance mechanisms in managing information asymmetry in public-private relationships. The study uncovers key activities for gathering, sharing and transforming information when using digital technologies.

Originality/value - This study draws on IPT to study public-private relationships undergoing DT. The study links contractual control and coordination as well as relational governance mechanisms to informationprocessing activities that organisations deploy to reduce information uncertainty and equivocality.

Keywords Digital transformation, Information asymmetry, Contractual governance, Relational governance, Public-private relationships, Information processing theory

Paper type Research paper

\section{Introduction}

The role of information technology in supporting information and process integration within and between organisations is well established (Kache and Seuring, 2017; Venkatraman, 1991). More recently, the concept of digital transformation (DT), driven by new information and communication-based technologies (e.g. data analytics, smart sensors), has attracted scholarly attention (Brinch, 2018; Lanzolla et al., 2018). As these digital technologies may greatly enhance the quantity and quality of data available for decision-making (Waller and Fawcett, 2013), DT is seen as an important enabler for smart maintenance of production assets (Bokrantz et al., 2020).

This study draws on information processing theory (IPT; Galbraith, 1974), which posits that organisations deploy information-processing activities (Daft and Weick, 1984) that best address the amount and type of information asymmetry they are faced with (Bode et al., 2011). More specifically, we build on IPT and distinguish two types of information asymmetry uncertainty (lack of information) and equivocality (ambiguity of information; Zhao et al., 2018). While gathering more data may help mitigate information uncertainty (Bode et al., 2011), addressing equivocality may require cognitive skills to transform data by ordering and presenting data in a logical way. Both information uncertainty and equivocality are likely to be present in public-private relationships undergoing DT, with the use of digital technologies increasing the amount and quality of available data, while also offering enhanced possibilities for analysis and transformation. Thus, digital technologies can affect information acquisition and transformation processes in these inter-organisational relationships (IORs).

At the same time, collaborative activities of information gathering and transformation may be difficult to organise in public-private relationships due to public and private organisations' divergent goals and incentives as well as their differences in terms of institutional backgrounds, values, practices and decision-making processes (e.g. Caldwell et al., 2017; Roehrich et al., 2014). This raises concerns about how public organisations may govern information-processing activities with their private partners for the purpose of enhanced decision-making (e.g. timing of maintenance activities). Inter-organisational governance - the formal and informal rules of exchange between partners (Cao and Lumineau, 2015; Roehrich et al., 2020) - supported by contractual and relational governance mechanisms (Poppo and Zenger, 2002), may be instrumental in addressing possible information asymmetries resulting from separate yet interdependent data collection and analyses by public and private organisations.

A consideration of the role that governance mechanisms play in leveraging the high volumes of data generated by digital technologies addresses several knowledge gaps in the 
inter-organisational governance and DT literatures. First, although prior studies on DT have loosely mentioned the possibility of increasing data generation (and so potentially addressing information uncertainty; Sternberg et al., 2021) and digital technology's analytical capabilities (which may address information equivocality; Frank et al., 2019), no detailed and comprehensive study has investigated DT's impact on information asymmetry and processing activities. Developing a more detailed understanding of information acquisition and transformation processes taking place in relation to information asymmetry is crucial in understanding DT and clarifies the relationships between contexts, outcomes and governance mechanisms (Formentini and Taticchi, 2016). Second, prior studies offer very limited insights into how contractual and relational governance mechanisms may support information acquisition and transformation processes (Kache and Seuring, 2017). Lumineau (2017), for example, argues theoretically that contracts influence information processing by specifying rules, operating procedures and incentive schemes, but he does not study in detail how contracts affect information acquisition and transformation nor the role of relational governance mechanisms. Furthermore, the notion that control and coordination dimensions of formal contracts affect their information-processing capacity has so far received limited empirical validation. This is a vital area as the effective governance of IORs is paramount to organisations' survival, requiring governance mechanisms to mitigate information asymmetry.

We address these gaps by studying how organisations in public-private relationships which increasingly use digital technologies to collect rich data (Baldus and Hatton, 2020) may deploy contractual and relational governance to support information acquisition and transformation in the context of DT, thereby reducing information uncertainty and equivocality. Public-private relationships represent a suitable research setting as both partners grapple with different information processing needs. For example, public organisations often have strict responsibilities imposed by the national government, meaning that if an infrastructure asset fails, the public organisation is held accountable even when the cause is poor maintenance by a private supplier. As a result, public organisations require more information than a private supplier would usually document. Differences may also emerge with regard to the interpretation of information. While a public organisation often prefers timely replacement of components to avoid breakdowns, private suppliers may use data to perform a risk analysis and consequently decide to stretch the lifetime of that component.

Building on IPT, we investigate four cases to address the following research question: How do contractual and relational governance mechanisms address information asymmetry in public-private relationships undergoing digital transformation? The investigated cases concern two Dutch public organisations outsourcing the maintenance of their transportation networks and their relationships with private suppliers. All four public-private relationships are undergoing DT because of increased use of digital technologies (i.e. the implementation of smart sensors to collect data about the health of the infrastructure networks). We draw on a rich data set including archival data, observations, contracts and interviews.

We contribute to extant research in two main ways. First, we advance DT research by showing how DT affects information uncertainty and equivocality as well as information gathering and transformation activities in public-private relationships as a specific type of IORs. We illustrate that digital technologies address information uncertainty by generating more data and equivocality through enhanced transformation activities. Our findings also show that organisations need to develop their data gathering and transformation capabilities, as increased data availability does not imply that these data can readily be accessed or that they make a meaningful contribution to decision-making. Second, our study theoretically and empirically investigates the roles of contractual and relational governance
Managing
information
asymmetry

1147 
IJOPM

41,7

mechanisms in IORs undergoing DT, thus extending prior governance literature. Both governance mechanisms are important, but they each have different roles in supporting information processing. Our findings show that contractual control and coordination are more effective in supporting data-gathering activities, while relational governance underpins information transformation. The use of contractual control clarifies partners' obligations in gathering and sharing data and needs to be complemented by coordination clauses that guide data-gathering activities, with clauses that help accessing the right data type and quality as well as appropriate incentive schemes. Relational governance supports data transformation as it facilitates openness about what data are gathered and what meaningful information that data could be turned into. The development of relational norms enhances partners' understanding on what data is required for what purposes and fosters pro-active information sharing.

The remainder of the paper is organised as follows. First, we review relevant literature on DT, IPT and inter-organisational governance. Subsequently, we elaborate our research approach after which we present our findings. We then discuss theoretical contributions and practical implications and highlight limitations and future research opportunities, before concluding the paper.

\section{Theoretical background}

\subsection{Digital transformation of maintenance service delivery}

DT involves the implementation of data-driven and software-managed processes, which in turn generate large volumes of data that can be used to increase information availability, transparency and visibility in IORs (Sternberg et al., 2021). Following prior studies, our paper treats data as the raw material of information, thus data are unprocessed and an asset awaiting transformation into information (Sivarajah et al., 2017). Data gathered using digital technologies are seen as "the new oil" (Hartmann et al., 2016), highlighting the importance of exploiting and refining data to attain high performance levels for a focal organisation and their supply chain. Various digital base technologies (i.e. the Internet of Things (IoT), cloud services, big data) enable a wide range of front-end technologies (i.e. smart-manufacturing, -products, -supply chains and -working) concerned with operational and market needs along four dimensions (Frank et al., 2019). Smart maintenance (Bokrantz et al., 2020; Huang et al., 2020) comprises elements of both smart manufacturing (e.g. smart sensor data, enabling predictive maintenance) and smart working (e.g. virtual reality, enabling interactive and realtime guidance of maintenance tasks; Scurati et al., 2018). Data-driven decision-making (e.g. prediction and prescription of maintenance actions) and external integration (e.g. sharing and consolidating heterogeneous data sources with external parties) are being noted as key dimensions (Bokrantz et al., 2020). Suppliers are an important source of valuable data, as the digital technologies embedded in their offerings may predict failures and prescribe actions to be taken. As such, the ubiquity of data, computing power and analytical capabilities may help drive performance of maintenance service providers (Olsen and Tomlin, 2020). As suppliers are progressively assuming responsibilities regarding product and process innovation (Blome et al., 2013), information sharing and collaboration with suppliers (Huang et al., 2020) provide ample opportunities for organisations to improve their productivity and to transform processes.

While prior studies offer some insights with regard to how data are being gathered, much less is known about how data are analysed and interpreted (Yu et al., 2019), especially in situations where possibilities and responsibilities for data collection and analysis are distributed across dyadic relationships including public-private ones. A more detailed understanding of how organisations organise these activities to manage information needed for decision-making is crucial for DT. 
2.2 Information processing needs for digital transformation in public-private relationships

Drawing on IPT, we argue that in the face of environmental uncertainty - that is, "the difference in the amount of information required to perform the task and the information already possessed by the organisation" (Galbraith, 1973, p. 5) - organisations deploy information-processing activities (i.e. gathering, processing and communicating information; Daft and Weick, 1984) that best address information asymmetry (Bode et al., 2011; Galbraith, 1974). Information asymmetry is referred to as either the absence of information (uncertainty) or the messiness/ambiguity of information (equivocality) (Zhao et al., 2018). Whereas gathering more data may help mitigate information uncertainty (Bode et al., 2011), equivocality requires cognitive skills to transform data including ordering and presenting information in a logical way. This is particularly pertinent when the information required is ill-structured, difficult to evaluate and requires more than one individual for interpretation (Daft and Lengel, 1986).

Prior work has addressed organisations' approaches to reducing information-processing requirements (Galbraith, 1973). Here, IPT helps to explain organisational behaviour "in terms of information that must be gathered, interpreted, synthesised, and coordinated in the context of decision-making" (Burns and Wholey, 1993, p. 110). IPT has, for example, been used to assess the impact of internal manufacturing complexity on the organisations' triple bottom line (Wiengarten et al., 2017) and to study the mechanisms managers can use to create internal strategic consensus (Rosado Feger, 2014). Recent work has extended IPT to an inter-organisational level, addressing how organisations develop information-processing capabilities to deal with supply chain disruptions (Bode et al., 2011), sustainability-related uncertainty (Dahlmann and Roehrich, 2019) and cost management challenges in new product development (Ellram et al., 2020). However, relatively little attention is paid to IORs' capacity to gather and process information ( $\mathrm{Yu}$ et al., 2019), despite the increasing importance of joint efforts between focal organisations and their suppliers to systematically gather and analyse information, especially in light of the possibilities and challenges that DT brings.

Furthermore, the majority of prior (IPT informed) operations and supply chain management (OSCM) studies focus on relationships involving private organisations, despite the fact that information processing is considered essential to "bridge disagreement and diversity" (Daft and Lengel, 1986, p. 556) between two organisations that may have different objectives and values as is often observed in public-private relationships (Caldwell et al., 2009). These public-private relationships are defined as "any long-term collaborative relationships between one or more private actors and public bodies that combine public sector management or oversight with a private partner's resources and competencies for direct provision of a public good or service" (Kivleniece and Quelin, 2012, p. 273). Public-private collaborations are now a global phenomenon, with the United Kingdom leading the deployment of such relationships with approximately 360 publicprivate partnerships (PPPs; a form of public-private relationships) for a total value of $€ 58 \mathrm{bn}$ that have been initiated in the past 10 years (EPEC, 2017). During the same period in the Netherlands, 34 PPPs were initiated that account for a total value of $€ 10 \mathrm{bn}$ (EPEC, 2017).

Although prior OSCM studies have highlighted the characteristics of public-private interactions (e.g. Roehrich and Lewis, 2014; Zheng et al., 2008), recent publications call for further empirical research of relationships between public and private organisations (e.g. Mishra and Browning, 2020). While the aim of the private actor is often to appropriate created economic value via private rents, the aim of public organisations is to maximise predominantly appropriable (social) value for various beneficiaries (Klein et al., 2010). Combining the efforts of private, value-maximising firms and more social-interest-driven public organisations (Hart, 2003), public-private collaborations intersect the operating logic
Managing
information
asymmetry

1149 
IJOPM

41,7

of both political and economic markets and may feature a more heterogeneous, interdependent set of interests when compared to private-private relationships (Kivleniece and Quelin, 2012; Mahoney et al., 2009). These relationships may therefore carry potentially vital gains in terms of efficiency, innovation and ability to draw upon unique resources and capabilities residing in the private sector (Cabral, 2017) and outperform either (public and private) sector working alone (Lepak et al., 2007; Roehrich and Kivleniece, 2021).

By the nature of their cross-sector design, however, these collaborations are also exposed to divergent incentives and objectives as well as resource and capability gaps underlying each sector (Hartmann et al., 2014; Quelin et al., 2019). For instance, these relationships may face substantial governance costs tied to the complex nature of underlying contracts and the additional monitoring, control and enforcement needs - not least due to potentially divergent knowledge bases, goals, values, incentives and behaviours, organisational routines and capabilities (Caldwell et al., 2017; Quelin et al., 2017; Rangan et al., 2006). It is vital to avoid coordination failures in these relationships which may stem from, for instance, cognitive limitations (bounded rationality) of those who design and implement coordination mechanisms (e.g. failure to recognise interdependencies, attention constraints which may limit monitoring effectiveness) and from underlying cultural differences (as presented by private and public organisation's goals and values) (Gulati et al., 2012; Kalra et al., 2021). Thus, adopting optimal governance mechanisms is crucial in such relationships to align incentives, allocate decision rights and ensure information flows for maximising underlying partners' commitment (Cabral et al., 2019; Klein et al., 2019) and may address a central tension in terms of how to coordinate across public and private organisations. Hence, public-private relationships offer a fruitful context for studying how the effective deployment of governance mechanisms can support data gathering and transformation activities and help manage information asymmetry in the context of DT.

\subsection{Inter-organisational governance}

IORs are highly dependent on effective coordination and control using reliable information to meet performance targets including, for instance, high-quality maintenance services. This is particularly important in the context of DT, as the adoption of digital technologies provides opportunities for increasing data quantity and quality, while also presenting challenges in terms of how to gather and process data. High interdependence between partnering organisations "increases the need for a common formalised language in order to enable the exchange of information" (Gattiker and Goodhue, 2004, p. 433). Inter-organisational governance mechanisms, i.e. the formal and informal rules of exchange between partners (Cao and Lumineau, 2015; Olsen et al., 2005; Roehrich et al., 2020), may provide such a "common language". In line with IPT, we argue that contractual and relational governance mechanisms may act as frames and filters that influence how organisations collect data generated by using digital technologies and transform data into information that can be used and shared for decision-making in the IOR (Lumineau, 2017; Thompson, 1967).

Contractual governance in the form of written, legally enforceable contracts helps to define roles and responsibilities between exchange partners and support the framing of predetermined promises and obligations for resolving potential disputes and conflicts (Luo, 2002). OSCM research, in particular, has stressed the multiple roles of contracts in managing buyer-supplier relationships, including those in public-private exchange settings (e.g. Kapsali et al., 2019; Roehrich et al., 2021; Zheng et al., 2008). Contracts include a wide range of provisions (depending on contract type such as performance-based contracts; Essig et al., 2016) that can potentially be used to control a counterpart's behaviour and safeguard against possible opportunism (Steinbach et al., 2018), coordinate inter-organisational processes, adapt exchanges in the face of environmental uncertainty and even codify lessons learned regarding efficient inter-firm collaboration and contracting (Howard et al., 2019; 
Selviaridis, 2016). Contracts can also be used as framing devices aimed at eliciting productive responses by counterparts (Selviaridis and Van der Valk, 2019; Weber and Mayer, 2011).

Contracts influence information processing by specifying explicit rules and operating procedures, planning and incentive systems (Halldórsson and Skjøtt-Larsen, 2006; Hartmann et al., 2014; Lumineau, 2017), which may stimulate suppliers to improve their processing capabilities (Glock et al., 2017). Control and coordination clauses can both facilitate information gathering by explicitly stipulating information exchange (including type, frequency and quality) between contracting parties (Faems et al., 2008; Jayaraman et al., 2013; Mayer and Argyres, 2004). Coordination clauses can influence the way information is interpreted (Daft and Weick, 1984; Fiol, 1994) by facilitating communication and supporting information transfer (Mesquita and Brush, 2008; Zheng et al., 2008) as well as by joint transformation between partners (Puranam et al., 2006). For example, the study by Zheng et al. (2008) showed that contracts can function as a knowledge repository where information is being stored and accessible for contracting partners in addressing information asymmetry. Prior studies (Schepker et al., 2014; Tushman and Nadler, 1978) argued that the more comprehensive contractual control and coordination mechanisms are, the greater the ability to process information and deal with uncertainty.

Compared to contracts, relational governance mechanisms depend on trust and social norms among partners, fostering a joint approach to addressing information asymmetry (Poppo et al., 2008) in buyer-supplier relationships (e.g. Chakkol et al., 2018; Roehrich and Lewis, 2014). Trust has been positioned as minimising the probability of opportunism and conflict as well as increasing collaboration and information exchange (Carey et al., 2011; Inkpen and Tsang, 2005). Relational norms, referring to the shared behavioural expectations of partners involved in a relationship (Cannon et al., 2000; Heide and John, 1992), imply a bilateral expectation that parties will proactively provide useful information to their partner in support of the ongoing relationship. Trust and relational norms based on flexibility, openness and information sharing are instrumental in governing IORs where information processing across organisational boundaries is of essence such as in complex projects (Chakkol et al., 2018) and public-private relationships (Roehrich and Lewis, 2014). Relational governance may influence the processing of information through social processes (Poppo and Zenger, 2002). In the presence of trust, parties are more likely to expend effort into gathering and joint transformation of information. Trust is vital for effective information sharing, operational linkages and cooperative norms among partners (Ghosh and Fedorowicz, 2008). Increasing levels of relational governance and trust between partnering organisations help to jointly transform information to address asymmetry in a dyad when offering more complex services (Kreye et al., 2015). The flow of information in relationships characterised by high levels of trust allows for enhanced synthesis of information; partners actively provide useful information, thereby frequently soliciting and exchanging private information (Carson and John, 2013; Heide and John, 1992).

Overall, in the context of DT, where the provision of maintenance services is increasingly enabled by digital technologies, generating and sharing information in IORs relies on effective coordination and control through governance mechanisms. At the same time, our understanding of the roles of both contractual and relational governance mechanisms in gathering and interpreting information remains limited.

\section{Methods}

3.1 Research setting, design and case selection

We employed a multiple-case design (Yin, 2009) to investigate the role of governance mechanisms in addressing information asymmetry in four public-private relationships, embedded in two public organisations undergoing DT (Table 1). Our design thus yielded
Managing
information
asymmetry

1151 


\section{IJOPM} 41,7

Public organisation - Road
(The Netherlands)
Responsible for main road and waterways
and water management in the Netherlands

Road A

\section{Private} organisation (supplier)

Public and private organisation's objectives

Information needs of both public and private organisation

Prior relationship
Consortium of: (1) a

large supplier (20,000 employees) specialised in construction; and (2) a medium-sized supplier (175 employees) specialised in hydraulic engineering Road B

Consortium of: (1) a large supplier (46,500 employees) specialised in electro-technical installations; and (2) a medium-sized supplier (180 employees) specialised in construction Road (public): Safeguard public interests (e.g. availability, security) and maintain aging infrastructure with limited budgets in a sustainable manner, while also dealing with extended responsibility (Road is publicly accountable in case failures occur, even if supplier's actions caused it) Suppliers (private): Increase volume of maintenance activities (e.g. remain focussed on preventive rather than predictive maintenance, so that more maintenance activities can be performed), thereby potentially decreasing the availability of infrastructures

Road (public): Is reliant on up-to-date information about the health of assets and performed maintenance from their suppliers to more efficiently manage assets and monitor availability/safety of the network due to their extended knowledge of the suppliers regarding assets to transform data

Suppliers (private): Requires historical data from Road's systems to calibrate degradation models for assets in order to detect failures and better plan future maintenance activities

No prior relationship with either supplier responsibility. Requires technical
Public organisation - Rail

(The Netherlands)

Responsible for main railways in the Netherlands

Rail A

Rail B

Medium-sized

supplier (275

employees)

specialised in construction and maintenance of railroad systems

Large supplier (6,500 employees) specialised in construction and maintenance of railroad systems

Rail (public): Safeguard public interests (e.g. availability, security), maintain aging infrastructure with limited budgets, and perform effective traffic management on the railroad network. Rail also needs to deal with extended responsibility (Rail is publicly accountable in case failures occur, even if supplier's actions caused it) Suppliers (private): Increase volume of maintenance activities (e.g. remain focussed on preventive rather than predictive maintenance, so that more maintenance activities can be performed), thereby potentially hindering effective traffic control

Rail (public): Requires up-to-date information about the health of assets and maintenance activities to re-route or re-schedule trains in case of failures, check suppliers' performance, and monitor availability/safety of the network due to their extended responsibility Suppliers (private): Requires the newest data from inspection trains to complement their own inspection data to monitor the condition of assets. Builds on historical data from Rail's systems to better plan future maintenance activities

No prior relationship with current supplier
Second consecutive contract. Previous contract period: 5 years
Table 1.

Case (organisation) characteristics 


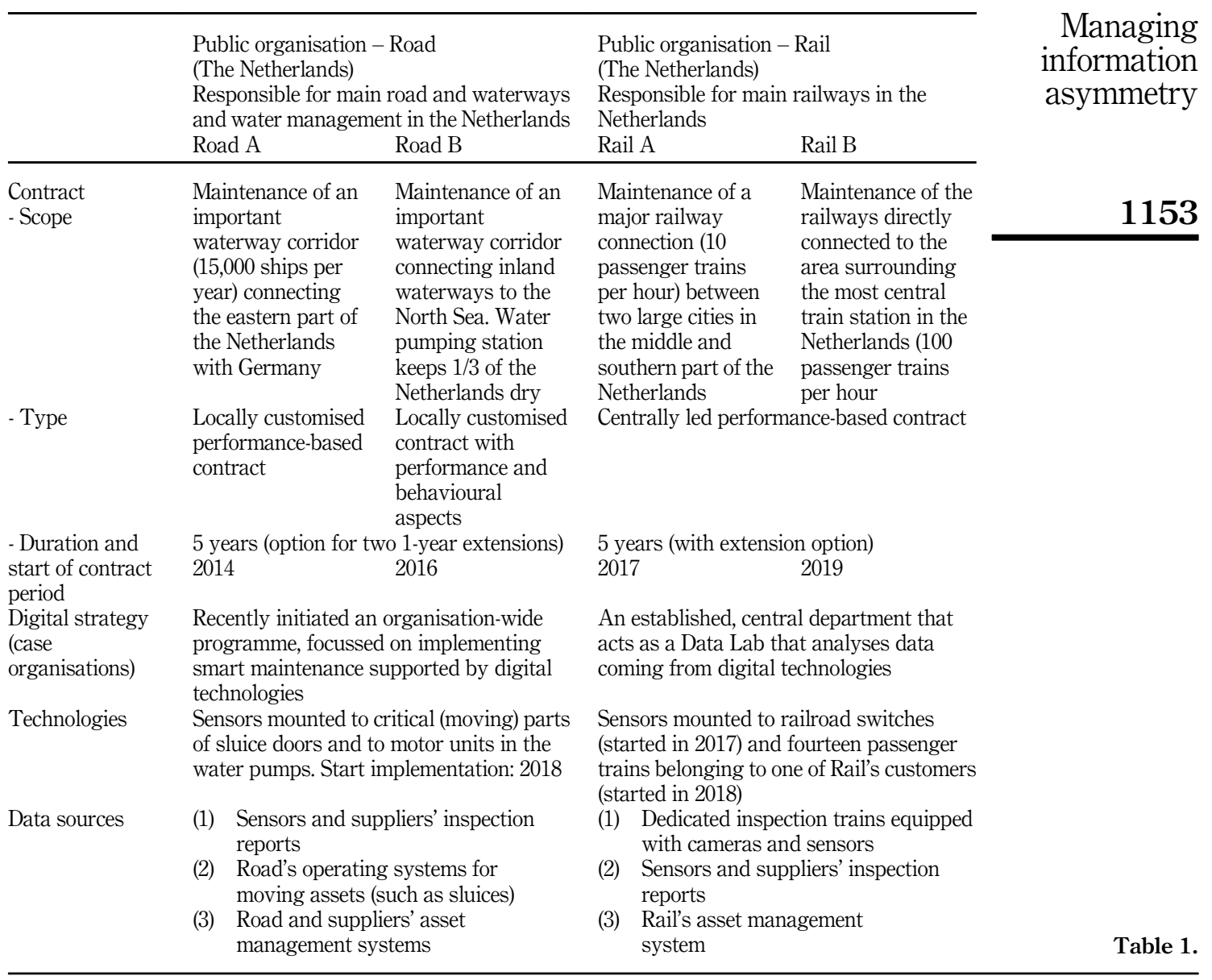

multiple observations of contractual and relational governance challenges faced by the two public buying organisations we studied (Golden-Biddle and Locke, 2007). Our research setting was the Dutch infrastructure sector where public organisations have been tasked with managing critical infrastructure networks and have started to adopt digital technologies (Baldus and Hatton, 2020) to enhance infrastructure network management and to stimulate smart maintenance (Bokrantz et al., 2020). At the same time, both public organisations depended on the specialist resources and competencies of their private suppliers for leveraging data produced by these technologies to realise smart maintenance and sharing valuable information related to the networks' condition (RAE, 2012). The infrastructure networks to be maintained were thus fully owned and operated by the public organisations and maintained by private suppliers. The first case organisation (Road) was responsible for all motorways (including bridges and tunnels) and waterways (including sluices and water pumps) in the Netherlands. The second case organisation (Rail) was responsible for the entire railway network in the Netherlands. 
IJOPM

41,7

The four cases were selected after conducting exploratory research including pilot interviews and the collection and analysis of secondary data (Table 2). The investigated cases had a number of unique qualities that made them logical candidates for sampling (Shah and Corley, 2006) and we employed a theoretical sampling logic (Patton, 1990) based on the following key criteria. First, each of the four investigated public-private relationships involved the recent adoption of digital technologies (i.e. mounting smart sensors to critical assets to gather more and better data) that may enable improving infrastructure management and maintenance. Second, we purposefully sampled relationships in which the public organisations rely on their private suppliers for real-time data about the assets (resulting in information uncertainty as private suppliers may not be sufficiently incentivised to provide public organisations with complete data) and in which historical data in databases of the case organisations are incomplete, of insufficient quality and/or messy. As a result, our cases were characterised by different degrees and types of information asymmetry, that is, uncertainty and/or equivocality. Lastly, all four relationships involved public tenders and supplier selection based on best value evaluations and were governed by a contract with durations of at least five years and concerning substantial revenues for the private suppliers involved. This speaks to the notion of a detailed contract and the importance of contractual governance in these investigated relationships. Following Schilke and Lumineau (2018, p. 2849), who argued that "it seems likely that the contracting process may play a less central role in simpler, shorter, or more exploitation-oriented types of alliances", we purposely selected cases that involved longer, more collaborative types of relationships to ensure that relational governance mechanisms were present and used. We had a rare opportunity to have extensive access to employees and (archival and contractual) documents at both case organisations, which enabled us to explore governance mechanisms fully.

\subsection{Data collection and sources}

Our study combined primary (observations, interviews), contracts and secondary data sources (vision and strategy documents, presentation slides, and government and industry reports). We collected data using a two-stage strategy. During the exploratory research stage (March-September 2018), eight pilot interviews and selected site visits at both case organisations were conducted and archival data were collected. Analysing these data sources helped to establish an interview protocol and to select appropriate cases. The subsequent indepth case research stage (November 2018-December 2019) involved the lead author conducting 20 interviews to collect data on each of the four investigated cases in real time (during the ongoing public-private relationship undergoing DT). Also, contracts and various other archival data were collected (Table 2) to achieve data triangulation (Jick, 1979). Data gathering from multiple sources continued until theoretical saturation was achieved and was key to understanding and unpacking relational and contractual governance and their role in addressing information asymmetry in detail. For example, access to contracts proved instrumental in complementing our interview data with respect to how contracts enabled data collection activities by the case organisations, thereby helping to reduce information uncertainty. The following sections explain in detail the data sources we collected and how they aided our study.

3.2.1 Archival data and observations during site visits and meetings. We collected and analysed 25 documents as well as observational data produced during site visits and meetings (approximately 55h). Overall, the archival data and observations provided a deeper understanding of the case organisations, the sector, key suppliers, the maintenance data that were collected and the mix of contractual and relational governance mechanisms employed by case organisations in relation to the implementation of digital technologies.

3.2.2 Contracts. We analysed 31 contract documents, including core agreements (e.g. specifying supplier responsibilities and scope), specifications of minimum 


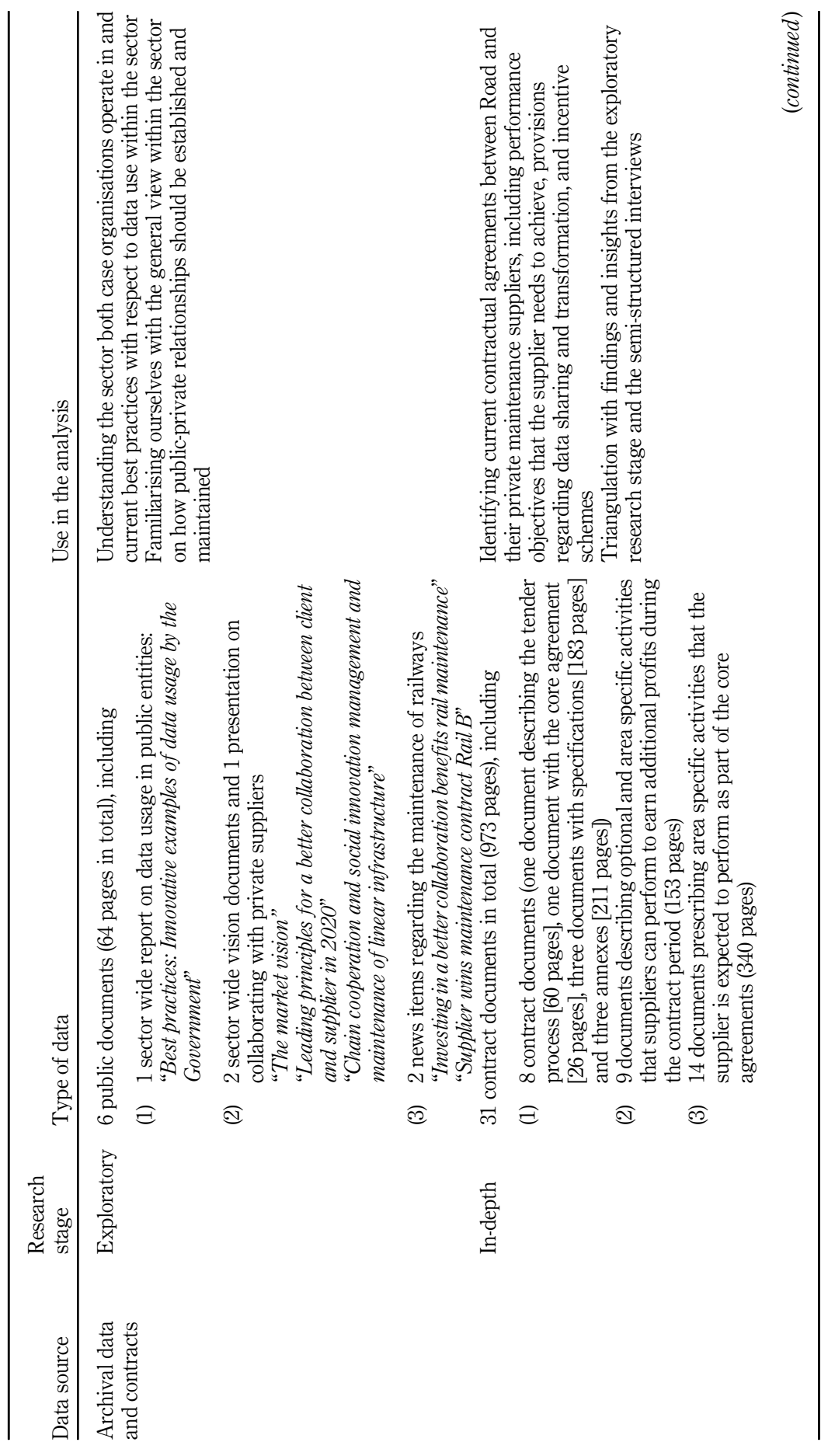

Managing information asymmetry

1155

Table 2

Main data sources and use of data 


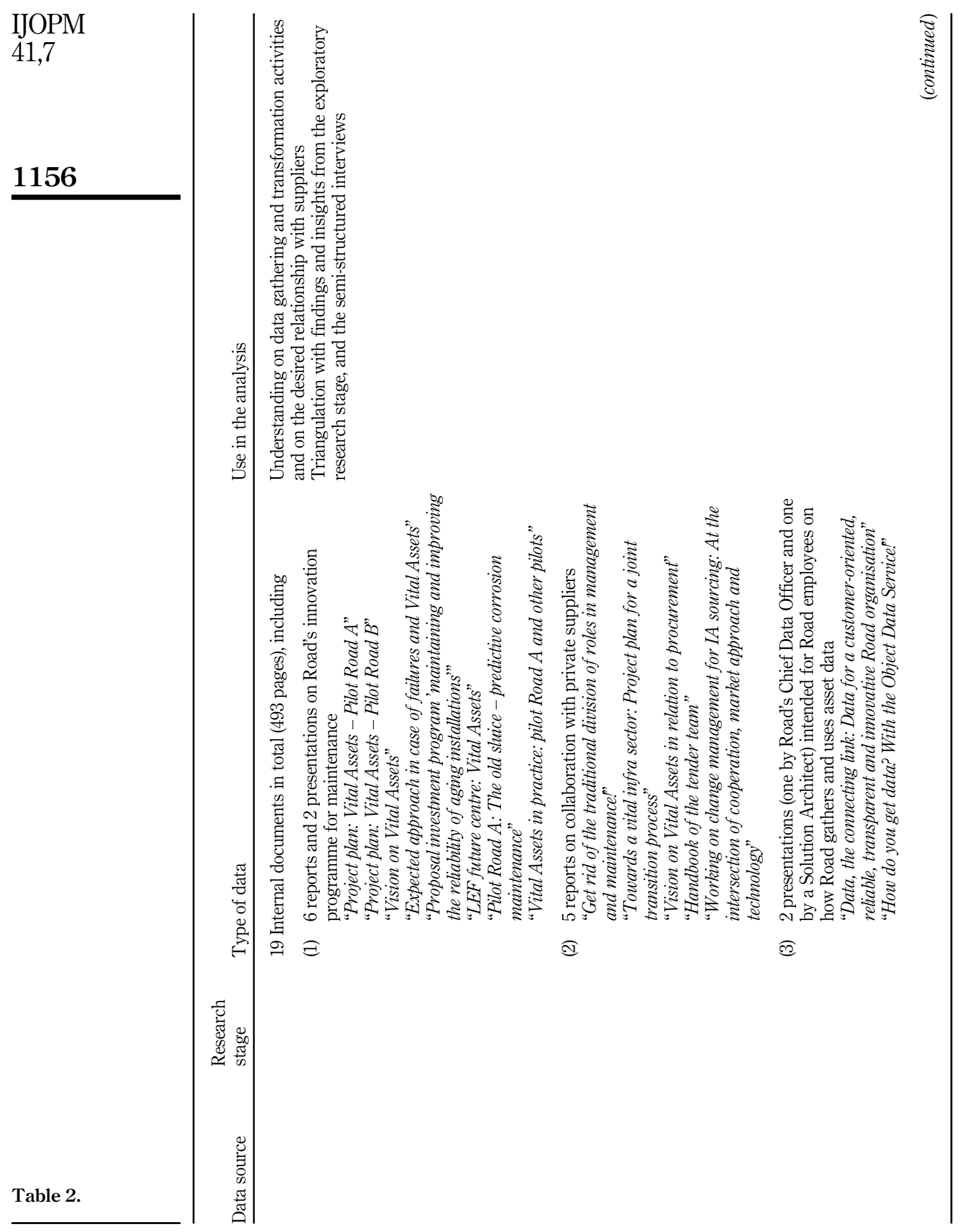




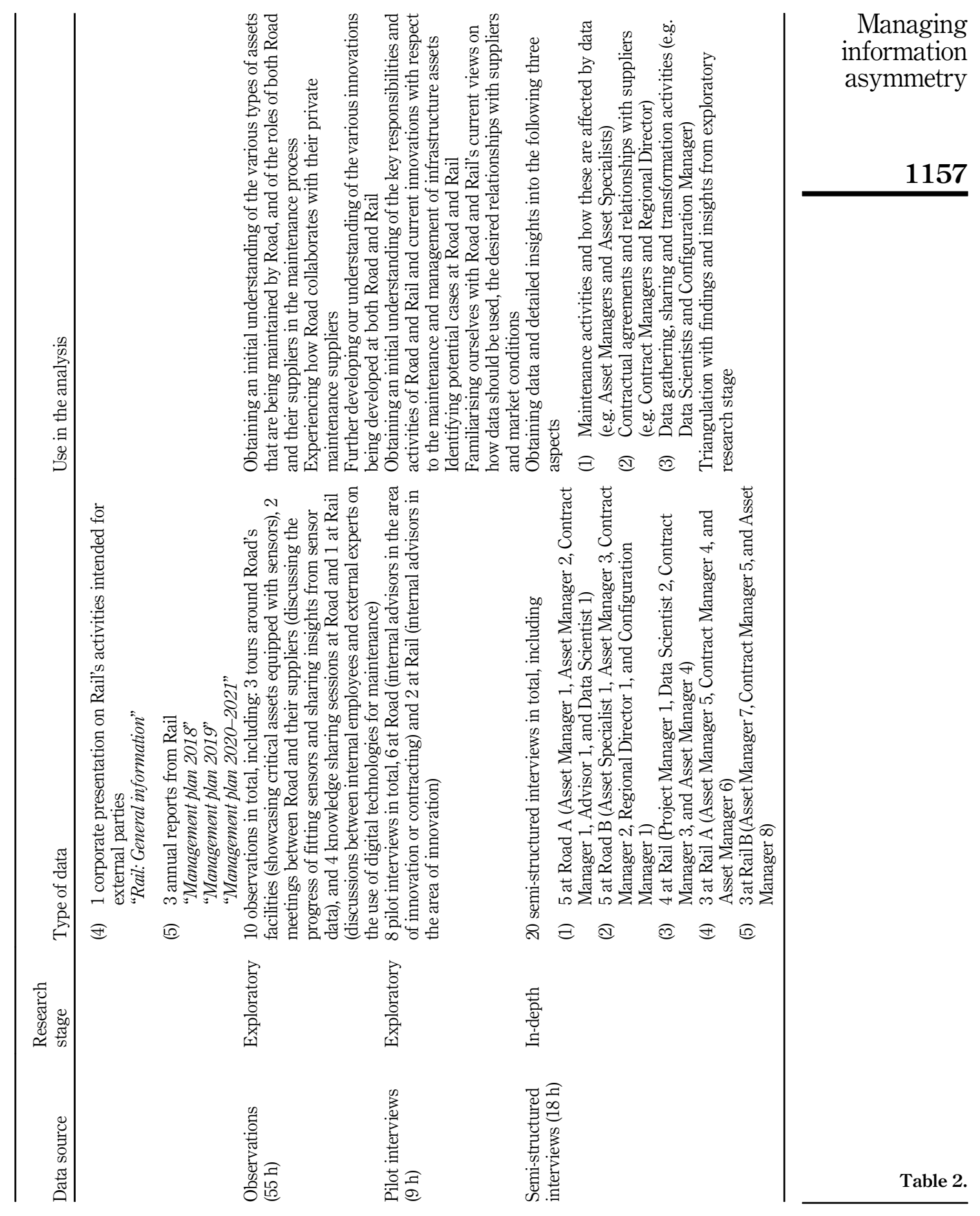


IJOPM

41,7

1158

requirements (e.g. asset availability) and general guidelines regarding what data needed to be shared and when (e.g. registering the nature of a failure, actions taken and components that were replaced). Various annexes captured region-specific details (e.g. permits or exemptions). This was vital to unpack how the contract (and specific control and coordination clauses) was used to support information-processing activities.

3.2.3 Interviews. We conducted eight pilot interviews (over $9 \mathrm{~h}$ ) with several advisors from both organisations that had a thorough understanding of contract management processes and/or digital technologies. We then prepared summaries of the most important points that provided us with an initial understanding of the two case organisations and their operations and helped us to uncover potential cases. During the in-depth case research stage, 20 interviews (over $18 \mathrm{~h}$ ) were conducted with knowledgeable people (Alvesson, 2003) with different lengths of tenure in disparate hierarchical and functional roles. An interview protocol was designed (Appendix 1) which we refined as the research progressed and new insights emerged. Semi-structured interviews included questions to help us understand the case organisations, the infrastructural assets involved and their maintenance requirements, past and current relationships with the private maintenance suppliers in focus, informationprocessing activities and the role of digital technologies in these processes.

We applied specific criteria and measures to ensure validity and reliability of our case study findings in line with literature recommendations (e.g. Gibbert et al., 2008; McCutcheon and Meredith, 1993; Yin, 2009). More specifically, we derived a research framework from extant literature and offered clarity about how data were collected and analysed (informant and data source triangulation). In order to increase generalisability, we built on analytical generalisation by seeking to identify patterns across cases (Ellram, 1996). The lead author coded each data source individually before discussing with the other three authors. This ensured not only a high degree of inter-coder reliability but also an in-depth understanding of the data set across the author team. All interviews were recorded and transcribed and subsequently reviewed by the respective informants to check for consistency. Finally, we maintained a database with all data sources used in the analysis to increase transparency and reliability. A detailed overview is presented in Appendix 2.

\subsection{Data analysis}

As recommended by Barratt et al. (2011) and Miles and Huberman (1994), data coding and analysis activities took place in parallel with data collection. Notes from the pilot interviews and observations, as well as archival data collected during the exploratory research stage, were assessed and discussed by the lead researcher and the second author to uncover interesting topics in the areas of digital technologies, contract management and maintenance at the case organisations. This helped in selecting the four cases and setting up the subsequent in-depth case research stage. Interview transcripts, contracts and archival data sources collected during the in-depth case research stage were subsequently coded using the data analysis software Atlas.ti.

Before we started the coding process, we identified several provisional themes (i.e. "data acquisition", "data transformation", "contractual governance" and "relational governance") from our literature review to guide our coding. As such, we ensured a clear link to prior literature, while providing flexibility to incorporate emerging themes such as "data needs", "registration of data", "bonus", "penalty" and "supplier behaviour" (i.e. open coding; Miles and Huberman, 1994). To assure the quality of the coding process, the lead researcher and the second author jointly discussed the initial open codes and established the initial coding structure, after which the lead researcher continued coding all transcripts and other documents. To enhance quality further, two research assistants each coded three transcripts from one of the cases, while the lead researcher coded all six interviews across both cases. 
Results between coders were compared to reduce potential biases or blindness to emerging constructs, with differences being resolved by trying to reconcile differing interpretations. For example, the codes "supplier attitude" and "supplier behaviour" were reconciled under the label "supplier behaviour". The results of this step were subsequently verified with the second author. Codes that could not be reconciled were critically evaluated by the lead researcher and the second author for their relevance (e.g. the code "replaceability of assets" was considered less relevant as it did not relate to information processing or governance; the code "maturity of system", which refers to asset management systems, was deemed relevant because it relates to information processing). In the end, 49 unique codes were identified.

Subsequently, the open codes were grouped into higher-order categories (e.g. "contract design" and "incentive schemes") using axial coding procedures. This resulted in ten secondorder codes capturing one or several first-order codes. Finally, the second-order codes were related to the four main concepts under study: "data gathering and sharing", "data transformation", "contractual governance" and "relational governance". The resulting final coding structure (Appendix 3) was used to analyse the remaining interviews, observations, contract documents and the archival data.

\section{Within-case analysis: information processing in public-private relationships} This section presents the within-case analyses. The analyses outline first how DT affected the relationships in focus and then presents data on how the organisations managed their information-processing activities using both governance mechanisms.

\subsection{Digital transformation in the public-private relationships at Road}

The two public-private relationships at Road included pilot projects as part of an organisation-wide digitalisation programme called "Vital Assets". In the past, Road's maintenance decision-making relied on an OEM's average life-cycle estimations and visual inspections (by Road or their private supplier). Usually, this resulted in maintenance taking place either too early or too late (e.g. a sluice door used to be maintained according to a predefined schedule or upon failure). As a result, Road's assets were either unnecessarily unavailable (because assets were being maintained while still working properly) or unexpectedly failing and causing potentially dangerous situations. Introducing sensors and advanced data analytics allowed combining sensor-generated data with data from Road's SCADA (a computerised control system used to operate assets) and asset management systems for better condition monitoring. Presenting the resulting information in a dashboard subsequently helped asset managers to handle assets more efficiently and suppliers to make more informed maintenance decisions that improved asset availability and user safety. For example, combining SCADA data on the sluice door movements with electricity usage of the door's hydraulic system provided valuable insights: "You can see the failure and you also know what the failure is" (Asset Specialist, Road B).

Having up-to-date information about their assets was essential as interviewees indicated that Road, being an executive agency of the Dutch government, had certain "extended responsibilities", meaning that they would always remain responsible for the availability and safety of their infrastructural network. Even with private suppliers maintaining the network's assets, Road should always keep itself informed about the state of the assets (e.g. to determine whether these are still safe enough to be used by the public). Road could not just point at the supplier in case a failure occurred: "If a supplier does something wrong, you can hold it against them. However, if the failure significantly hampers operations, then Road is ultimately responsible" (Advisor 1, Road A). Additionally, Road was obliged to work as transparently as possible as they were accountable to the government and to the public for
Managing
information
asymmetry

1159 
IJOPM

41,7

the actions taken. As such, they required not only basic data about performed maintenance activities, but also detailed data that could help prove that assets were safe enough to be used. The "Vital Assets" programme created awareness that Road needed to keep up with the technological developments that were changing the way maintenance was being performed. Moreover, instead of trying to "reinvent the wheel", they acknowledged that capabilities and knowledge resided with their supplier. As such, they opted for developing collaborative relationships with their suppliers and changed the contracts accordingly: "In our contracts we want to organise a different way of collaboration in the area of smart maintenance, including a different way of rewarding [suppliers] to avoid unnecessary costs and to share knowledge and data" (Towards a vital infra sector, p. 40).

With the "Vital Assets" programme Road developed an organisation-wide vision (captured in the "Vision on Vital Assets" document) with respect to how they should address the ongoing digital transformation that, among other things, enabled smart maintenance and management. Road viewed digital transformation to be an important element of their competitive environment and considered themselves to be at a crossroad: "It is expected that the sector will develop itself further, with or without Road. Even if Road does nothing, assets will become increasingly smarter. A lot is already happening in this area without us being aware of $i t$ " (Vision on Vital Assets, p. 3). Furthermore, Road acknowledged that they lacked the capabilities to implement digital technologies successfully, as for years they had increasingly been passing on responsibilities to their suppliers. Under this "market unless" principle as they called it, Road limited themselves to coordinating maintenance processes and refrained from requiring detailed information about their assets and maintenance performed. Suppliers, as a result, became fully responsible for assessing the actual states of assets and planning maintenance activities accordingly, and Road lost a significant part of their technical knowledge: "When we adopted the 'market unless' principle, it [technological knowledge] significantly disappeared at several places [regional asset management departments]" (Contract Manager, Road A). As suppliers became more knowledgeable about Road's assets, Road had become increasingly dependent on them for asset-related information as well as interpretation of that information, that is, "a possible dependence on the supplier who supplies data" and "a possible dependence on the supplier that performs data analyses" (Vision on Vital Assets in relation to procurement, p. 3). To reduce these dependencies and return to being a knowledgeable partner, Road decided to become more actively involved with their suppliers and with maintenance activities: "Now we see possibilities to build it [being a knowledgeable partner] up again. It is no surprise that programmes such as 'Vital Assets' triggered that old need" (Contract Manager, Road A). As a result, collaboration with private suppliers became a strong pillar in the Vital Assets programme and the pilots.

Road A concerned a sluice that is a vital node in an important waterway corridor connecting the Netherlands with Germany and a large water pump that regulates the water levels for several eastern provinces in the Netherlands. Road A invested some of the maintenance budget in sensors to measure sluice door corrosion rates and the stretching of the chains moving the doors (Project plan: Vital Assets - Pilot Road A, p. 9). The sensor data allowed the supplier to verify their degradation models and could also be combined with SCADA data to improve asset maintenance. Road B concerned a sluice in a water way corridor that acts as a gateway between the North Sea and the Dutch/European hinterland and a large water pump that regulates water levels. Road B invested in sensors that monitored the health of the hydraulic system that moves the sluice doors (Project plan: Vital Assets - Pilot Road B, p. 9). The private maintenance supplier did not contribute to this investment but was closely involved in decision-making as they were mounting the sensors to the assets and were, next to the regional asset management team, a main user of the data. 
Although both cases belonged to the same pilot project, closer inspection revealed regional differences in the levels of information asymmetry experienced. For example, while Road B found themselves confronted with issues with automated data transfer, Road A had no such problems. As a result, Road A was more able to access data and had relatively less information uncertainty than Road B. On the other hand, Road A had more difficulties with determining their information needs than Road B, leaving Road B with relatively less information equivocality. A selection of key evidence across both cases is shown in Tables 3 and 4, which is referred to throughout the text using numbering (e.g. [3]).

4.1.1 Information processing activities at Road A. Data gathering at Road A entailed manually registering results of planned inspections or causes of unexpected failures in Road's asset management system [1]. Additionally, it included coordinating the process of setting up a direct connection with the supplier's asset management system to enable seamless data sharing as indicated by the interviewees [2]. However, interviewees also suggested, "no explicit agreements were made" about the data that suppliers should gather and subsequently supply to Road A, as Road A's team did not exactly know what they needed [3]. Road A therefore experienced incomplete data sets and hence rather extensive information uncertainty. Transforming data into information, on the other hand, was found to be complex and interviews with several team members showed that the team struggled in determining their information requirements $[4,5]$. For example, the team did not know which behaviours of their assets were abnormal and indicated pending failures, nor what information they needed about these behaviours to predict future maintenance needs. Support from and close cooperation with the private supplier were needed to ensure that collected data were complete. The close relationship also included performing joint interpretation and transformation activities. For example, in order to develop key indicators for the performance dashboards, Asset Manager 2 set out to interpret the information shown by the dashboard jointly with his counterparts at the supplier: "You will always need each other with respect to this" [6]. As a result, information was less messy and information equivocality was relatively limited.

4.1.2 Contractual and relational governance at Road A. An annex of the contract specified that "the supplier must deliver area data once maintenance is completed" (i.e. control) and share it with Road's regional asset management team "so that Road can properly manage [the assets in] its area" [7, 8] (i.e. coordination). As the contract excerpts show, data-sharing clauses were not very precise as they referred to broader tasks (e.g. while the task "addressing failures" involved sharing data about the cause of failure and maintenance activities performed, what data was needed was not explicitly mentioned). Moreover, the contract failed to underline the importance of additional data that Road A needed to report on the degree to which they fulfil their public tasks (i.e. availability and safety of assets). The interviews confirmed the lack of explicit contractual agreements on data sharing [3] and explained that this made it difficult for Road to obtain the data they actually needed. The lack of understanding regarding what data was needed and why provided insufficient guidance and incentives for the suppliers to put in the efforts that Road A expected from them [10]. With respect to transformation, interviewees referred to a "progress report", mentioned in the contract, implying a requirement for the supplier to transform data [14]. This progress report typically contained information on the assets' health and on maintenance activities performed. No further evidence was found regarding contractually required information transformation activities. A plausible explanation was provided by the interviewees who indicated that it was difficult for the team to identify what information they needed and what the supplier should contribute $[4,5]$. This then inhibited developing specific contractual agreements. In parallel, an internal report described the need to redesign the current contract and incentive scheme to support knowledge sharing between Road A and their private suppliers [15].

\section{Managing information asymmetry}


IJOPM 41,7

\section{2}

Equivocality

\section{$\operatorname{Road} \mathrm{A}$}

Uncertainty

(1) In order to access needed data, Road A aimed to play a central role in data gathering: [1] "Road ultimately owns the objects. I think it is good if Road obtains and manages data itself" - Data Scientist 1

[2] "We are also looking for a link with our asset management system, which the supplier mainly works in" - Asset Manager 2

(2) Road A experienced difficulties with respect to determining the exact data they needed from their suppliers:

[3] "That [the availability of data] differs per object. Usually, no explicit agreements were made about this in the past" - Data Scientist 1

(1) Although Rail A possessed relevant data, their employees did not know their information needs and thus how the data should be transferred:

[4] "The biggest challenge lies in determining the information needs. What is the relevant information that we need for the various processes we have?" - Asset Manager 1

[5] "It would help if we had someone who acts as a customer, who explains how we can help him and what exactly he needs" - Data Scientist 1

(2) To make sense of data, Road A relied on their supplier's input:

[6] "My dashboard indicates action is required within three months. 'Do you have the same experience? Does this pump show you anything that something is wrong?' You will always need each other with respect to this" - Asset Manager 2

Contractual Governance $\quad$ Relational Governance

Information Acquisition
Table 3.

Findings and key quotes from Road A
(1) Contracts stipulated that Road owns the data and that suppliers must share relevant data (i.e. control)

[7] "We have 1 main objective. We call it 'making the $A B C$ ' of our contract area. Improve the quality of documents and data" - Asset Manager 2

[8] "The supplier must deliver area data once maintenance is completed, so that Road can perform proper management of its area" - Contract (Annex 3, page 45.)

(2) Contract prohibited (future) data sharing with other parties (control) [9] "But we want to be able to pass that data on to the next supplier" - Asset Manager 1

(3) Supplier takes advantage of vague agreements

[10] "The supplier tries to limit its efforts as much as possible. They simply think: 'I do not really have to do that, because the contract does not exactly detail what I have to do" - Asset Manager 1
(1) Road A's many requests for data led the supplier to think that Road A wanted to govern the maintenance activities the supplier was responsible for

[11] "There is friction between the supplier and Road. Suppliers find it strange that we want to know a lot and they say: you have us to manage that, why do you want to govern that?" - Advisor 1

(2) Trust was needed to ensure a supplier is not reluctant to share data

[12] "I think that it is mainly a matter of creating good connections and agreeing on what you are going to do" - Data Scientist 1

[13] "Interpersonal aspects and acceptance of each other's qualities play an important role. We must trust and strengthen each other" 'The Market Vision' document (page 7) 


\section{Contractual Governance}

Information

Transformation
(1) Basic transformation activities were requested from suppliers through the contract

[14] "The supplier must provide a progress report. This is used to determine what the performance of the supplier has been" Contract Manager 1

(2) Redesign of contract required to better support knowledge sharing

[15] "In our contracts, we want to organise a different way of rewarding [suppliers] in order to prevent unnecessary costs (including the use of capacity) and to support the sharing of knowledge and data" - 'Towards a vital sector' document (page 40)

\section{Relational Governance}

(1) Collaboration and common goals ensured most information was actually unlocked and interpreted in the same way

[16] "What I would also like to see is that market parties realise that by jointly working on this type of information, they can also organise the maintenance process much more efficiently" - Asset Manager 1

[17] "I want to discuss this with the supplier, so not simply supply the data and then have to rely entirely on the analysis that is being made. [...]I would like to do at least some of those processes together, to avoid discussion about the used data" Asset Manager 1
Managing information asymmetry

1163

Interviews with Road A's regional asset management team and internal documents indicated that building a trusting relationship was expected to foster shared behavioural expectations and motivate the supplier to gather and share data they seemed hesitant to share, despite the contractual incentives in place $[11,12,13]$. For example, while the supplier aimed to maximise its value from the contract by performing a lot of maintenance activities, Road A aimed for the supplier to go beyond mere profits and become interested in the condition of the assets and start to understand the importance of sharing data: "You want them [private supplier] to be pro-active and act as if they actually owned the assets in our area. That they inform us about what is happening and what should be done" (Asset Manager 1). To facilitate information transformation activities, establishing a common goal furthermore fostered the development of shared behavioural expectations [16]. For example, interviewees described that instead of passively supplying data to suppliers so that they can verify their asset degradation models, the team aimed to analyse at least part of the data collaboratively, thus seeking to enhance both parties' understanding of maintenance needs [17]. Asset Manager 1 pointed out that this is vital "to avoid discussion about the used data". Stated differently, collaboratively interpreting the information derived from analytical models helped to reduce individual biases and to avoid the situation where Road A would become dependent on the private supplier to interpret information: "You have to look out for the situation where the supplier gets the raw data and modifies it. The next could be: 'Look Road, this is interesting for you' and that they try to sell that information back to us" (Advisor 1). Establishing a common goal (i.e. more efficiently organised maintenance) motivated both parties to invest in the collaborative information transformation activities required to achieve this goal and helped the private suppliers to maintain assets in a timely and resource efficient way while helping Road A to increase asset availability.

In sum, these findings suggest that Road A experienced extensive information uncertainty due to difficulties in determining their exact data needs and incomplete data sets regarding their assets. A combination of imprecise contractual control and coordination clauses described mainly how suppliers were supposed to share data, as opposed to which data needed to be shared. As such, for the private supplier it was not clear what data needed to be shared. Road A tried to support their contractual agreements by building a collaborative relationship and establishing bilateral expectations as to motivate the supplier to go beyond the "letter of the contract" and focus on the "bigger societal gains" rather than merely their 
IJOPM

41,7

1164

own goals. This included the supplier assisting Road A with their public task to offer reliable and safe infrastructures with a high level of availability. However, these relational governance mechanisms were not fully effective in complementing incomplete contract terms, resulting in only limited increases in suppliers' understanding of what data to gather and share and in Road A still missing some of the data they require.

Road A experienced limited information equivocality as they worked closely together with the private supplier to perform transformation activities effectively. As the contract only specified the requirement of progress reports to be prepared by the private supplier, joint transformation activities strongly relied on relational governance mechanisms, that is, creating a trusting and collaborative relationship and establishing common goals.

4.1.3 Information processing activities at Road B. Data gathering at Road B entailed data on results of planned inspections and causes of unexpected failures. However, in contrast to Road A, Road B's supplier only needed to register these data in their own asset management system due to the direct link between their and Road B's supplier's asset management systems. Despite this direct link, certain fields in Road's databases were nevertheless left empty because the technical configuration did not allow seamless data transfer [18]. As a result, Road B experienced extensive information uncertainty (when compared to Road A). Moreover, information uncertainty resulted from differing interpretations of data completeness between the private supplier and Road B. For example, while the supplier believed that a short description of the activity performed was enough ("button pressed"), Road B also expected some contextual information (e.g. the cause of the failure) [19] and thus required additional data from the supplier. Information transformation activities also proved to be complex for Road B, as the data they received from the supplier was provided in the wrong format [20] and hence messy. For example, while Road B specified specific fields in a standard form to capture information (e.g. number of hours worked, type of failure), the supplier simply put all this information into the "description" field and left the other fields in the form blank. This required Road B to reorganise the supplier's data, leading to long transformation lead times and information being obsolete before it was even used [21]. Interviewees furthermore mentioned that Road B's system could not manage 3D files, forcing the team to convert these into 2D files and leading to a loss of data [22]. Road B acknowledged that reducing the messiness of the supplier's data required flexibility to deviate from the initial agreements, as these turned out to not be specific enough.

4.1.4 Contractual and relational governance at Road B. Road B's contract had the same data-sharing clauses as found in Road A's contract, that is, control clauses to ensure data gathering and coordination clauses to govern data sharing. The contract also specified the direct link between the asset management systems of both partners, including which data fields should be connected to ensure correct and complete data [25]. The interviewees, however, indicated that the asset management system had been upgraded after the start of the contract, while the related contract clauses referred to a prior version of system [26]. Hence, the direct link could not be established. Contract clauses related to information transformation activities were sparsely present as interviewees indicated that specifying information requirements in contracts was not easy: "The biggest problem is that internal information needs and contract requirements are not working together" [32]. Road B considered clauses to "set things in stone", while flexibility was actually needed to deal with changing information needs: "You have to be flexible; you cannot afford to be rigid anymore" (Contract Manager 2). For example, following a major incident at one of their sluices, Road B needed additional information to demonstrate that users of the sluice had not been endangered and that sufficient actions had been taken to avoid similar issues in the future. As such situations were difficult to forecast, the contract had to allow for requiring additional information from the supplier. Lastly, the specification document of Road B's contract included clauses requiring the team to organise recurring performance evaluation meetings 
Road B

Uncertainty (1) Road B did not receive all required information due to wrong configurations in the connection between their own system and their supplier's system and because of misunderstandings about what data were actually needed:

[18] "Not enough data are being sent and we still miss a lot of things. We are working very hard on fixing this" - Configuration Manager 1

[19] "At the beginning they filled out too little information. [. . .]. The data should provide us with enough information, and not just things like "finished" and "button pressed"-

Contract Manager 2

Equivocality (1) The data in Road B's database did not have the correct data format and the extended time it takes to fix the data format rendered the data useless:

[20] "The information is described in the description, but that is not in the form of data. If you want to analyse that, you have to search in the text boxes and order that first" - Asset Manager 3

[21] "It is not real-time information due to the large time difference. It is not reliable and it is not correct anymore" - Asset Manager 3

(2) Road B's system could not handle all types of file formats they received

[22] "We are twenty years behind with this within Road. We "flatten" everything to $2 D$ [while supplier sends 3D]. [...] We do not have the facilities to embrace 3D. You understand of course that we lose a lot of data" - Asset Manager 3

\begin{tabular}{ll}
\hline Contractual Governance & Relational Governance \\
\hline
\end{tabular}

Information Acquisition
(1) Contracts stipulated that Road owned the data. Suppliers had to share to avoid penalties (i.e. control); penalties were found to be ineffective

[23] "If the supplier does not want to transfer it, the supplier does not meet the contract requirements. Then you get a penalty or even a breach of contract" - Configuration Manager 1 [24] "They do get a penalty, but that is sometimes much less than what they can save if they do nothing" - Asset Specialist 1

(2) Contracts also included the requirement to connect data systems (control)

[25] "We have had it [requirement to connect systems] included in the performance contract, which will have it [data from supplier] transferred automatically." Configuration Manager 1

(3) Agreements about what to share were vague and inconsistent (coordination)

[26] "What they have to fill out is in the agreement. But these agreements are based on a very old system" Configuration Manager 1
(1) Suppliers seemed hesitant to share all maintenance data [27] "But they do not put all their cards on the table. It is true." - Configuration Manager 1

(2) Road invested in open communication and tried to refrain from penalising suppliers immediately to avoid a blaming game

[28] "We are open and transparent regarding the needed and available information" - "The Market Vision" document (page 6)

[29] "What does the supplier need and what do we need? That is how we collaborate. It is no longer about pointing fingers to each other" Configuration Manager 1

[30] "Our goal now is to collaborate more with the market. Previously, we had a more steering role" - Contract Manager 2

(3) Road sought to enhance current relationships through two-way sharing [31] "We are not only knowledge seekers, but also knowledge bearers. So we can also return knowledge to them" - Configuration Manager 1

\section{Managing information asymmetry}

\section{5}

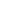


IJOPM 41,7

\section{Contractual Governance}

Information

Transformation

\section{6}

(1) Misaligned contract agreements hampered transformation [32] "The biggest problem is that internal information needs and contract requirements are not working together. If you have specified your internal information needs, the contract should actually be accommodating to it" -

Configuration Manager 1

(2) Contract stipulated that recurring meetings should have been organised to jointly interpret and transform information [33] "The Principal organises one or more meetings per period to discuss the evaluation reports" - Contract (Specification 1, page 38)

\section{Relational Governance}

(1) Road sought collaboration to receive all information [34] "That is our pilot. That they process all malfunctions directly in our system" - Asset Manager 3

[35] "We look at the asset in the field. Is it properly maintained, and does it [information in the system] match the current state of the asset? And that you then assess together" Contract Manager 2

(2) Closer collaboration was also needed to induce flexibility and motivate parties to look beyond contract agreements

[36] "Not only our contracts have to change, also our behaviours and attitudes. It is not the same as five or more years ago. [...] You have to flexible, you cannot afford to be rigid anymore" - Contract Manager 2

Table 4.

with the supplier [33], but did not contain any specific information on meeting content and parties' roles. As a result, Road B had to rely on other governance mechanisms to determine the roles of the parties involved and to ensure that the right information is obtained.

To promote data sharing, the supplier was penalised in case they did not deliver, but this penalty was found to be insufficient to deter divergent behaviour: "They do get a penalty, but that was sometimes much less than what they saved if they did nothing" (Asset Manager 3). Several members of Road B's regional asset management team however indicated to refrain from penalising suppliers as much as possible [29], as this might make the supplier hesitant to share data in the future [27]. Contract Manager 2 indicated that the team focussed instead on collaboration ("Our goal is to collaborate with the market"), as to build a trusting relationship and to enhance information sharing [31]. By showing that information was needed for proper asset management rather than for penalising the supplier, and that flexibility was required to respond to changing information needs [36], Road B hoped to move the supplier away from strictly following contractual agreements: "A supplier always checks: "what is in it for me?" They will not provide an additional service that is not prescribed in the contract" (Contract Manager 2). Investing in collaboration also paid off with respect to Road B's information transformation activities, because the collaboration involved establishing a common goal. Contract Manager 2, for example, mentioned that Road B and the supplier started to assess data of the assets jointly [35], which helped to combine expertise and allowed for developing a shared understanding.

Overall, Road B experienced extensive information uncertainty. Road B's difficulties with determining their data needs resulted in imprecise and ineffective clauses to control access to data, while basing clauses to coordinate the data transfer (i.e. the how of data sharing) on wrong system configurations led to incomplete data sets regarding their assets. Moreover, incentive schemes appeared to be ineffective which led to additional issues with data sharing. Road B also invested substantial time in relational mechanisms including building a collaborative and trusting relationship with their supplier, which fostered open information sharing and provided flexibility to deal with gaps in contracts. Similar to Road A, Road B also 
experienced that relational governance was insufficient in complementing incomplete and poorly specified contractual mechanisms, causing Road B to miss data still.

Road B showed that it experienced limited information equivocality, as Road B was able to leverage their supplier's expertise for the purpose of transformation activities. The joint transformation activities were mainly supported by relational governance (including collaborative relationships, common goals and trust), while contractual governance was sparsely used to outline the basics of the joint activities (e.g. having recurring meetings).

\subsection{Digital transformation in the public-private relationships at Rail}

For decades, Rail has relied on data collected by specialised inspection trains, equipped with sensors and cameras, to manage and maintain their assets. Inspection trains, however, only scan the rail network a couple of times a year, and hence, data could only be used to take preventive maintenance decisions. In order to obtain real-time data, Rail invested in sensors, mounted to the rail network and partnered up with a semi-public train operator to obtain more continuous data streams by fitting 14 passenger trains with sensors that provided Rail with daily reports from which potential "harbingers" of failures could be detected (Management Plan 2019, pp. 19-20). Furthermore, a Data Lab (established in 2017) combined different data flows and developed failure prediction algorithms. These two developments enabled Rail to "use data in a smart way, which means that we, for example, together with suppliers prevent failures and obtain earlier insights into when an object needs to be replaced" (Management Plan 2018, p. 39) and to manage their network: "Without data, you have no control and no oversight. We need that data to know how our assets perform and how it affects train movements" (Project Manager 1).

Similar to Road, Rail also faced an "extended responsibility" with respect to the availability and safety of the rail infrastructure and hence required timely and accurate information about their assets. When maintenance activities took too long or were performed too late (leading to extended periods of non-availability of railway segments and possibly to unsafe situations), both the public and the Dutch government would hold Rail accountable and not the private maintenance suppliers. As a result, Rail A's asset management team preferred to exert more control in the relationship with their private supplier: "We have to build in even more clauses [in the contract] where we can take more control. This is because we are the ones who, if things go wrong, are on the evening news again and not the supplier" (Asset Manager, Rail A). Rail B illustrated the difference between their goals and the supplier's as follows: "The supplier has commercial interests, besides that they have heart for the railways and enjoy performing maintenance. But in the end, the supplier also looks at what they can earn with it. Rail has a different assignment. We have to keep the rail track available for carriers and travellers" (Asset Manager, Rail B). While suppliers were satisfied with data demonstrating that they had completed their job (e.g. descriptions of failures and measures taken), both Rail $\mathrm{A}$ and $\mathrm{B}$ required additional data about the impact of maintenance on availability (e.g. length of the activity, potential differences between expected maintenance time vs actual time, etc.) to safeguard societal interests (e.g. a safe rail network).

In order to capitalise on the opportunities provided by DT, Rail took the lead in implementing digital technologies, rather than relying on suppliers or collaborating with them. Rail believed that in their specific sector they were in the best position to take the lead as they had access to more data than individual private suppliers did: "A supplier only has data from their own area, and thus has far fewer data points than we do. So, we are the only ones in a position to do these predictions" (Data Scientist). Embracing digital technologies enabled Rail to predict potential problems regarding network availability using data from their national database, for example, regarding heating elements in railroad switches: "We built sensors in the tracks to measure the temperature of the railroad to avoid switches being flooded with snow, because otherwise you have an availability problem” (Asset Manager, Rail B). Although Rail led
Managing information asymmetry

1167 
IJOPM

41,7

the implementation of digital technologies, they still required specialised input from their private suppliers: "As an asset manager, I would very much like to know: 'is my infrastructure deteriorating in the way we expect? And do the maintenance activities performed by a supplier benefit that pattern or does it deteriorate too much? '" (Asset Manager 4). Private suppliers' expertise in maintenance helped Rail to understand their assets better, to smarten the actual maintenance activities and to achieve efficiency gains. Despite significant investments in digital technologies, Rail's technicians (who had been trained in the management and maintenance of technical systems) continued to be largely unfamiliar with the use of data and their potential. This resulted in a low adoption rate of data in asset management processes, and suppliers being only sparsely allowed to use their own digital technologies to smarten the maintenance of the area they were responsible for: "I think we are still at a stage where we are slowing down the suppliers. This stems from our historical conservatism" (Asset Manager 5, Rail A).

Rail A focussed on the north-western part of the Netherlands and included the management and maintenance of the railroad network including a pivotal central train station. A major failure at that train station would cause the majority of the Dutch timetables to be disrupted. Rail B mainly worked on railroad networks in the south-eastern part of the Netherlands that connected several major cities. Rail had centralised its maintenance service tendering process and aimed to ensure that regional asset management teams acted in a uniform way. However, closer examination of the cases revealed regional differences with respect to levels of information uncertainty and equivocality experienced and the mix of contractual and relational governance mechanisms deployed. These differences are discussed in the next sections. The evidence referred to has been captured in Tables 5 and 6 .

4.2.1 Information processing activities at Rail A. Both the regional asset management team and the supplier manually entered data into Rail's central asset management system [37]. These data helped with monitoring assets' conditions and the supplier's performance and allowed enriching the data Rail gathered themselves. The supplier was contractually required to collect data about their operational activities and to share that data with Rail upon request [38]. However, interviewees raised concerns about the private supplier's apparent reluctance to share data: "Certain information is not provided, not correct, not complete, or does not meet the requirements" [39]. Nevertheless, information uncertainty was relatively limited due to the extensive data-gathering activities performed by Rail A. Data transformation was generally performed by Rail A, but interviewees indicated challenges regarding the resources available to check and verify all supplier-provided data, which seemed uncleaned and incomplete [40]. As a result, the database looked messy and Rail A needed to perform structuring of the data, leading to a continuing discrepancy between the information in Rail A's systems and reality. Another challenge was that Rail A struggled to determine which data were crucial and how to use them [41]. Overall, Rail A faced rather extensive information equivocality.

4.2.2 Contractual and relational governance at Rail $A$. The contract explicitly stipulated that the supplier should gather and share data on Rail A's assets [42, 43] (i.e. control). However, being short on capacity [44], the team was unable to check whether they received all data they required, which allowed the supplier to reduce efforts in areas that were not checked: "Then the supplier's 'beeping system' [acting only when the other party asks for something ('beeps')] comes around: 'I do not deliver; and I will see if I hear something'" (Contract Manager 4). Suppliers simply "forgot" to share gathered data when Rail A did not actively enforce the contractual agreements that stipulated data sharing [45, 46]. In order to manage data transformation activities, Asset Manager 5 indicated that he heavily relied on contractual control, with the contract stipulating that suppliers should transform maintenance and inspection data to information that demonstrates whether requirements have been met [50]. This again required Rail A to meticulously check the 
Rail A

Uncertainty (1) Rail A and their supplier jointly populated Rail's A asset management system with data: [37] "That is a system where we just share the data. They [the supplier] see everything in it, but I see that too" - Asset Manager 6

(2) The supplier also collected data about their own activities and shared data with Rail A upon request:

[38] "We want those suppliers to track and record this [data performance maintenance activities], and when we say "now I want to see it" you have to deliver it" - Asset Manager 5

(3) There were some concerns that the supplier did not share all data they had and that the quality of data was not always of appropriate quality:

[39] "We have experienced this every once in a while, that certain information is not provided, is not correct, is not complete, or does not meet the requirements" - Asset Manager 5

Equivocality (1) A large part of the data in Rail A's database did not correspond to the actual situation at Rail A's assets and, hence, should have been cleaned:

[40] "In the past, this [data cleaning] has not yet been done correctly at Rail. There are a kind of improvement steps going on now. However, you are not completely up-to-date in your database with respect to what is actually outside at the moment" - Asset Manager 6

(2) Even though they had the data, Rail A did not know what they wanted to do with the data: [41] "The question is: what willyou do with it? Because yes, data are provided, but if you do not do anything else, you still do not have a KPI for your senior management and for your team" Contract Manager 4

Contractual Governance $\quad$ Relational Governance

Information Acquisition
(1) Rail specified clauses with respect to data usage (i.e. control) [42] "There is a certain clause in the $P B C$ contract that clearly states that this and this must be reported by [supplier] to [Rail], and then [Rail] must act on it" - Asset Manager 6

[43] "It is stated there that every renovation that takes place or anything maintenance-related that is of importance for this equipment, that they must share it with us. The contract just states that they [maintenance suppliers] are the ones who are responsible" - Asset Manager 6

(2) Contract enforcement (i.e. control) was crucial, but had been deteriorating over time

[44] "Enforcement needs to be tightened, as the department that used to enforce has been cut by $50 \%$ " - Asset Manager 6

[45] "Then the supplier's "beeping system" comes around. I do not deliver and Ill see if I hear something" Contract Manager 4

[46] "Suppliers does not do as we have contracted. Sometimes the supplier "forgets" to deliver [data] and keeps quiet about it until we ask for it" Contract Manager 4
(1) Afraid of the consequences (e.g. penalties in case data showed that the supplier did not achieve all contract requirements), Rail A's supplier aimed to share the minimum accepted amount of data

[47] "Data about maintenance activities is something the supplier makes a fuss about, so you have to ask for it all the time. They prefer to keep this a bit foggy" - Asset Manager 6

[48] "Certain things that might put the organisation in a bad, or in a less good, daylight. . . the supplier tries to cover this a bit" - Asset Manager 6

(2) Transparency might lead to noncompliance with tender regulations and thus Rail and their supplier refrained from sharing all data

[49] "Transparency is not desirable. Maybe not from [Rail] either, but I am not sure about this" - Contract Manager 4 
IJOPM 41,7

\section{0}

\section{Contractual Governance}

Information

Transformation

(1) Rail A required transformed information from suppliers and strictly checked everything they received

[50] "They have to demonstrate on a monthly basis, by means of data, that the requirements we set in the contract, that they meet them" - Asset Manager 5 [51] "You also have to have strict control over everything that you receive. We are now trying to get more employees available to do the checks, because that is simply very important. [We need] to ensure that the IT guys have sufficient capacity to continue to do this well' Asset Manager 6

Table 5.

\section{Relational Governance}

(1) Rail A distrusted any information shared by the supplier's higher-level managers

[52] "The management of such a supplier are sent to bring a certain message. They try to make things more beautiful than they are" - Asset Manager 6

(2) Open communication with the supplier's operational level employees was established which led to additional information transformation [53] "You have the technical men that try to perform their work in a way that works best for the railroad tracks. So sometimes they say something that they perhaps should not have said" - Asset Manager 6

(3) Rail A refrained from establishing a common goal with the supplier to avoid non-compliance with tender regulations [54] "I fully understand what is behind it, the compliance issue. It just makes it very difficult for us to achieve a common goal with our supplier in the way that we would like" - Asset Manager 6

submission of transformation reports and their contents, which was unfeasible because of limited capacity [51].

Limited evidence was found regarding a systematic use of relational governance mechanisms in support of data gathering and sharing. In fact, rather than having a trusting relationship, interviewees indicated distrust between Rail A and their suppliers. Fearing consequences, Rail A's suppliers shared a minimal accepted amount of data (i.e. just showing enough to keep Rail A satisfied) [47] and even hid specific data that might put them in a bad daylight [48]. For example, when an inspection by the supplier revealed an issue at a specific asset that could easily be fixed, the supplier sometimes chose to fix it without reporting it to Rail A to avoid a potential penalty. While Contract Manager 4 argued that relational governance was not invoked in order to comply with European tendering regulations [49], the team did (at times) resort to relational governance mechanisms. For example, increasing collaboration and information sharing with the supplier's operational employees helped Asset Manager 6 to find out that the supplier's managers highlighted information that supported them in meeting contracted KPIs, while being less clear regarding information that was less favourable to their performance [52, 53]. Setting up joint information transformation activities through relational governance mechanisms was found to be challenging, however, because common goals and increased levels of collaboration could provide the current supplier with an advantage over competitors, which would be in conflict with tendering regulations [54].

In sum, Rail A experienced limited information uncertainty due to their own extensive data-gathering activities and strong control over the data that were collected by their 
supplier. Control was exercised by having clear contractual agreements that indicated which data the supplier should collect and how data should be shared. Additionally, Rail A aimed to check actively the completeness and correctness of the data collected by the supplier. Staff shortages, however, prevented Rail A from checking all data, and consequently, their databases contained gaps. Relational governance was not developed as Rail A was afraid that too much collaboration and openness with the private supplier would violate EU tendering regulations. Instead, the strong focus on contractual control seemed to create distrust between Rail A and the private supplier even.

Rail A experienced extensive information equivocality as they performed most transformation activities themselves. The few transformation activities to be performed by the supplier were governed by contractual coordination clauses specifying which data needed to be transformed into what kind of information (i.e. what purposes the information would serve). As these clauses were not clear on how information would be further interpreted by both parties, the supplier presented information only selectively (to ensure that the supplier's own work was presented in the best possible light), which then required Rail A to actively check incoming information. Again, staff shortages prevented Rail A from conducting a complete and systematic check of all incoming information.

4.2.3 Information processing activities at Rail B. Similar to Rail A, Rail B used the central asset management system to store and share data regarding maintenance activities performed on assets and inspections: "It actually contains everything about such a failure. What happened, what they did about it." [55]. Additionally, Rail gathered data using sensors and inspection trains $[56,57]$. This suggested that information-gathering activities were well developed and that information uncertainty was relatively limited as Rail B received the required data. With respect to data transformation, Rail B relied heavily on data scientists in their Data Lab to, for instance, transform heat sensor data to predict possible freezing of railroad switches so that they could be serviced on time. However, Asset Manager 7 [58] stated that the supplier was involved in data transformation (e.g. jointly discussing performance deviations to understand better why performance was not as expected) because of limited internal resources and because inputs from the supplier were required to transform data. Considering the inputs required from the supplier, equivocality was relatively extensive.

4.2.4 Contractual and relational governance at Rail B. Contractual coordination mechanisms played a dominant role in motivating the supplier to gather and share data [59, 60], with Rail B enforcing the contractual agreements by exerting control [61]. More specifically, the regional asset management team regularly inspected their assets and occasionally (e.g. when assets were found to not have been properly maintained or when inconsistencies emerged between their database and reality) requested additional data to investigate what happened and to what extent the supplier was responsible [59]. Similar to Rail A, Rail B had not negotiated any specific contractual agreements with respect to transforming data, other than the transformations required to demonstrate contract compliance [65]. Instead, Rail B mostly relied on their own employees to perform transformation activities.

The regional asset management team felt that the supplier did not share all available data [62] and indicated that trust was limited. The team therefore opted for more flexible contract application, as to build a more trusting relationship: "There has to be a bit of a balance in it [enforcing penalties], you cannot address everything. But it [managing incentives] has to stay manageable" (Contract Manager 5). Moreover, Rail B pursued openness by explaining the need for the contractual agreements [64], and how they would be applied, as to create shared behavioural expectations that could help in developing joint goals. By investing in relational norms (that acted as a reference guide on how both parties intended to collaborate with each other), the team could actively discuss and share information with the private supplier in
Managing
information
asymmetry

1171 
IJOPM 41,7

1172
Rail B

Uncertainty (1) Data about failures were directly entered into Rail B's asset management, both by their own employees as well as the supplier's employees

[55] "They do that, we use [software package]. It actually contains everything about such a failure. What happened, what they did about it" - Asset Manager 7

Equivocality (1) Rail B's employees tried to make sense of the data themselves but could not extract all information from the available data

[56] "I like the fact that we can now predict with data in advance which switches function and which switches do not, so that we can make adjustments" - Asset Manager 8

[57] "I rely on data from the inspection train. It [results from inspection train data] is all good and we are doing pretty well in terms of failures. But I also do not have everything in sight and neither do the inspectors" - Contract Manager 5

(2) To assist transformation activities, Rail B's area manager reached out to the supplier at times

[58] "We have a lot of contact with each other, we look for solutions together, and I try to inform them in time when I see problems coming up" - Asset Manager 7

\begin{tabular}{ll}
\hline Contractual Governance \\
\hline Information & Rail B's contract stipulated that the \\
Acquisition & supplier must share data upon \\
& request (i.e. control) \\
& [59] "If one of our inspectors has been \\
outside and comes back with the \\
message "that does not look good", \\
we [Rail] can request all their \\
inspection reports" - Asset Manager \\
8 \\
(2) \\
Rail B's contract also described the \\
role and responsibilities of the \\
supplier (i.e. coordination) \\
[60] "We prescribe what the standard \\
is. The qualitative standard it [assets \\
and related data] mustmeet and then \\
they [supplier] are free to try to \\
achieve this" - Asset Manager 8 \\
Rail became increasingly strict in \\
(3) \\
enforcing their contracts (control) \\
[61] "You can clearly see that Rail has \\
also more strictly enforced these \\
maintenance contracts in recent \\
years" - Contract Manager 5
\end{tabular}

Relational Governance

(1) Suppliers seemed hesitant to be completely transparent to Rail [62] "But they [supplier] also see things outside that we [Rail] have not seen that they are not going to report. That is just how it works" - Contract Manager 5

(2) Rail B did not blindly enforce the contract and their penalties all the time, but aimed to keep the supplier's point of view in mind and informed them about the need of contractual agreements

[63] "I especially think deviations should not be used for all that is not good, because if you impose a deviation for everything that is incorrect, a supplier will be paid nothing" -

Contract Manager 5

[64] "We do not push the contract to the background. Of course it is important that you have a good relationship, but it is also important to clearly explain what the contract is for" - Asset Manager 8
Table 6.

Findings and key quotes from Rail B

(continued) 


\begin{tabular}{ll}
\hline & Contractual Governance \\
\hline Information & (1) $\quad \begin{array}{l}\text { Rail B required their supplier to } \\
\text { transform data from their inspection } \\
\text { Transformation }\end{array}$ \\
& rounds into information about \\
& assets' condition and how assets \\
could best be maintained \\
[65] "Inspection reports, maintenance \\
plans. . we can request this on \\
demand." - Asset Manager 8 \\
(2) $\quad$ Rail B checked all the information
\end{tabular}

(2) Rail B checked all the information that was supplied by their supplier [66] "It is about procedural matters, but also just whether the information is good" - Contract Manager 5

\section{Relational Governance}

(1) Rail B aimed to invest in relational norms to foster open sharing of information and that motivated both parties "to go the extra mile", allowing flexible contract application [67] "In other contract areas that have the same supplier, the teams are much stricter, but the collaboration is not going that well over there and there is a lot of hassle" - Contract Manager 5 [68] "In any case, I like the fact that we have a good relationship with our [maintenance] supplier, which means that we get a lot of things done that do not happen in other regions. I think you will be better off with that in the end" Contract Manager 5
Managing information asymmetry

1173

Table 6.

support of the data transformation performed by Rail's employees and could motivate their supplier to go beyond the minimum requirements [63, 67, 68].

Overall, Rail B experienced relatively limited information uncertainty as data sharing was effectively supported by contractual control clauses that clearly specified which data the supplier needed to collect and how they should be shared. Contractual enforcement was very strict, involving the checking of incoming data and inspecting the work suppliers performed on their assets. Because of this strict enforcement, Rail B initially experienced limited trust at the supplier. In response Rail B increased openness by explaining why data were needed and why Rail B was strict in applying the contract, but also sought to apply the contract in a more flexible way (e.g. by not directly penalising for a deviation by the supplier). Rail B thus applied relational governance to a limited extent to complement the contract.

Rail B experienced rather extensive information equivocality. As Rail B performed the majority of transformation activities themselves, the contract only included some coordination clauses that guided the transformation activities that the supplier needed to perform to demonstrate contract compliance. Rail B noted, however, that their own expertise was insufficient to effectively transform all data and hence resorted to relational governance, that is, implementing relational norms to ensure that Rail B could tap into the supplier's expertise for performing the transformations.

\section{Cross-case analysis}

This section presents the main findings from the cross-case analysis. The role of contractual governance in relation to information asymmetry is first analysed, followed by the role of relational governance in relation to information asymmetry. Figure 1 illustrates the key concepts and their relationships as discussed in the cross-case analysis. It highlights that information gathering and sharing activities help address information uncertainty and that in IORs such activities are mainly supported by contractual mechanisms complemented with relational mechanisms. Information transformation activities help address information equivocality, and these activities are mainly supported by relational mechanisms complemented with contractual mechanisms. 


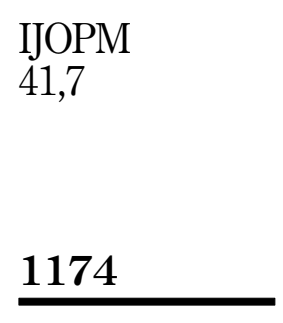

Figure 1.

The roles of contractual and relational governance mechanisms in managing information asymmetries

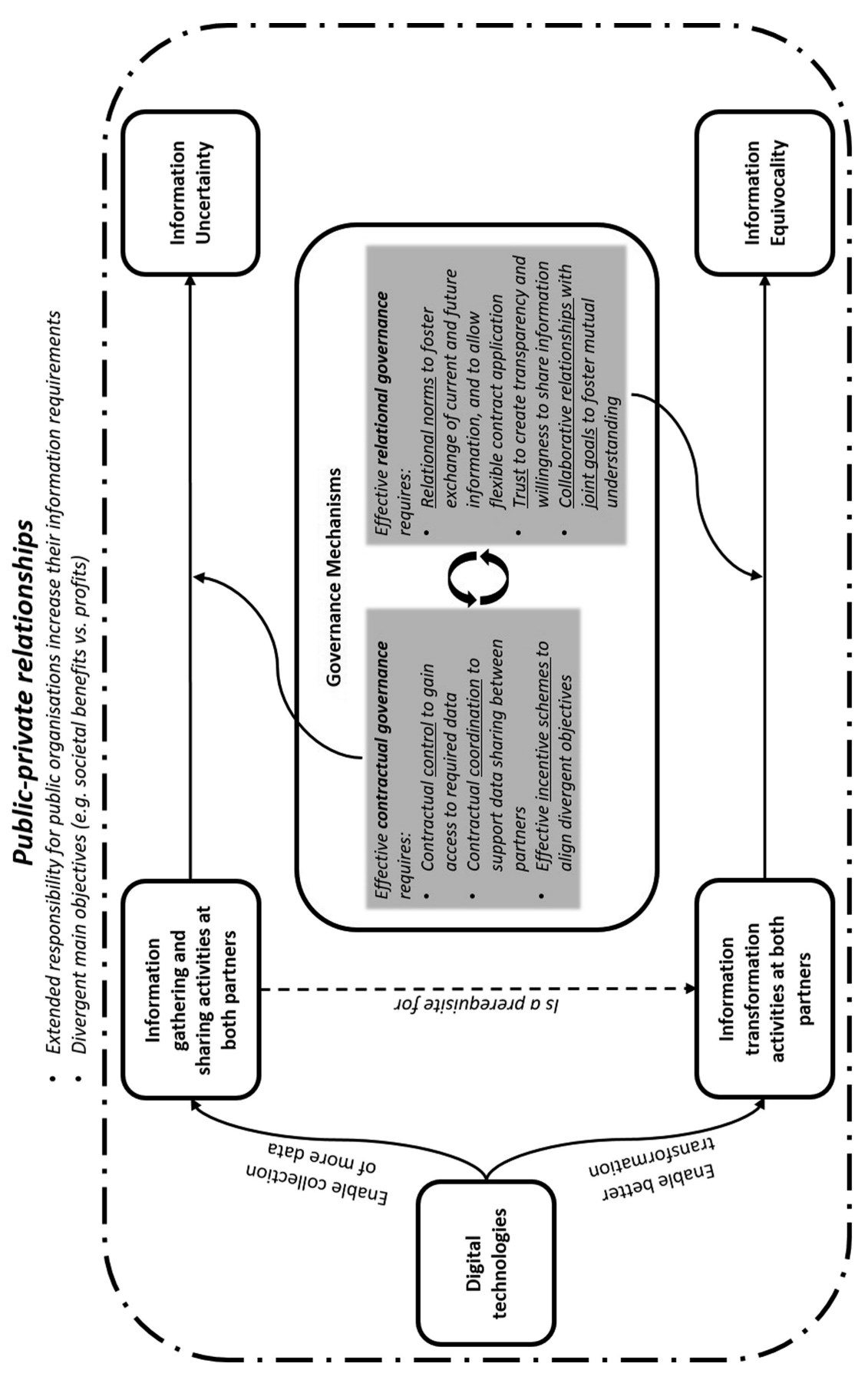




\subsection{The role of contractual governance in addressing information asymmetry}

Road A and B showed that ineffective contractual control and coordination caused issues with data-gathering activities, which in turn were associated with extensive information uncertainty. In contrast to the Road cases, both Rail A and B experienced limited uncertainty, as they were able to rely on effective contractual controls to manage their data gathering and sharing activities. As such, the cross-case findings demonstrated that information uncertainty was effectively addressed by using contractual control and coordination functions that allowed access to data collected at external parties. No evidence was found across the cases that contractual control and coordination could effectively be used to manage transformation activities and address information equivocality. In fact, Rail A and B experienced extensive equivocality while relying on contractual coordination to manage transformation activities, while Road A and B, which hardly relied on contractual governance, experienced limited equivocality.

Road's contracts required suppliers to share all data they collected regarding Road's assets and had incentive schemes tied to these requirements [8, 23, 24, 25]. Where Road A's contract contained provisions specifying how data should be shared, Road B's contract either lacked such provisions or contained provisions based on incorrect assumptions. Specific agreements indicating which data should be shared were lacking in both cases. Finally, both contracts experienced issues with the designed incentive schemes since Road A's supplier preferred to pay the penalty rather than invest money to be able to meet contract requirements. While Road A expected their supplier to act as if they were the owner of the assets, which would lead them to maximise the value for society as a whole and thus actively gather and share information, the supplier (as a profit maximising private party) in that relationship aimed to maximise their profits by doing as little as possible, thereby underplaying societal benefits. Road B's supplier followed the contract to the letter, questioning each data request, fearing to be penalised as it also sought to maximise its own value. Together, the cross-case findings suggested that contracts could help in establishing processes related to data gathering and sharing, provided that sufficiently clear specifications have been developed and incentive schemes have been appropriately designed. Too much focus on control (e.g. rigidly enforcing penalties) might render contracts less efficient as evidenced by the recent shift at Road towards a more collaborative approach with respect to their suppliers: "It is no longer about pointing fingers at each other" (Configuration Manager 1, Road A). Rail's contracts stipulated which data suppliers should share [42, 43, 60], but Rail had difficulties in specifying data needs and capturing these needs in contract clauses. Incoming data were actively checked and suppliers were penalised in case of non-compliance: "Those incentives work immediately. If you hit them in their wallet, you immediately hit them hardest and they are sensitive to that" (Asset Manager 6). This only worked, however, when contractual agreements were consistently enforced, as was the case for Rail A. Staff shortages inhibited Rail A to monitor all incoming data streams and check the completeness of data. This led to gaps in their database, as the supplier did typically not supply data that was not checked by Rail A. Rail B, on the other hand, did have sufficient resources to check all incoming data. This allowed them to enforce contracts better and to ensure that all data collected by the supplier was actually shared with Rail B.

Data transformation processes could not effectively be addressed using contractual control and coordination. Both contracts at Road required suppliers to periodically present progress reports by transforming inspection and maintenance data into asset condition information [14, 33]. Despite these provisions, both regional asset management teams felt they were not receiving what they really needed from the private supplier in terms of information. This inability to define information requirements by the public organisation inhibited capturing these requirements more explicitly in contracts $[4,32]$, causing the supplier to be confused about what data were required. Using the contract's control function
Managing
information
asymmetry

1175 
IJOPM

41,7

ensured that some basic data transformation activities took place ("the supplier must provide a progress report", Contract Manager, Road A), but these did not necessarily address Road's information requirements. The coordination function was only sparsely used for the purpose of data transformation in both cases. The contracts outlined, for example, the basics of the collaboration by prescribing regular meetings and the attendance of both partners, but did not stipulate the specifics about, for example, which partner should perform what transformation. Rail A's contract, in contrast, had more elaborate clauses aimed at coordinating data transformation activities, including specifications of the information Rail A wanted to receive [50]. As the contract was not clear on how information would be interpreted or used by the public organisation, the private supplier tended to present information selectively according to their interests. Rail B's contract delegated few transformation activities to the supplier [65]. For the majority of data transformation activities, Rail B relied on internal resources and capabilities.

In sum, both contractual control and coordination were found to be effective in addressing information uncertainty. Formal contracts turned out, however, to be less effective in addressing information equivocality.

\subsection{The role of relational governance in addressing information asymmetry}

Even though Road A and B invested in relational governance, both still experienced extensive information uncertainty. Rail A, which did not rely on relational governance, and Rail B, where relational governance played a minor role, actually experienced limited uncertainty. As such, the cross-case findings showed that information uncertainty could not effectively be addressed by investing more in relational governance. Rather, Section 4.2 demonstrated that uncertainty was effectively addressed by clear contractual terms that support data sharing between partners, and this should be complemented by relational governance to foster trust to create transparency. With respect to information equivocality, the cross-case evidence suggested that relational governance was effective for addressing information equivocality. Road A and B both relied mostly on relational governance to effectively manage their transformation activities, with a complementary role for contractual governance in setting basic rules for joint activities. In turn, Road A and B experienced limited equivocality. The Rail A and B cases show that not relying on relational governance, or only to a limited extent, while extensively using contractual governance actually increased equivocality.

The limited role of relational governance in gathering data from suppliers was especially evident at Road. Motivated by the organisation-wide strategy of "collaborating with the market" [28, 29, 30], Road began transforming their transactional relationships into more collaborative ones, thereby creating bilateral expectations regarding data sharing and how data could be used to more efficiently organise maintenance activities. Road B focussed on relational norms that fostered flexibility, which was needed to improve the interpretation of contractual agreements together with their private supplier. Rather than immediately penalising the private supplier for a contract deviation, the supplier first got an opportunity to explore the deviation and address it. The fact that the private supplier was allowed this "manoeuvring space" demonstrated flexibility and made them more willing to sometimes "go beyond and above" what was stipulated in the contract. Furthermore, while merely requesting data used to result in reluctance to share data by the private supplier, explaining more about data usage (by the public organisation) was found to increase the supplier's willingness to collect and share data. Trusting relationships enabled Road to increase transparency with respect to the contract clauses, which motivated the supplier to share data more freely $[12,28]$. Moreover, collaborative relationships helped both parties to build a mutual understanding and develop joint goals regarding data collection. Similar to Road B, Rail B's regional asset management team discussed deviations together with the supplier and 
identified joint solutions, which fostered data sharing by the supplier [58]. Discussing deviations and associated root causes built trust in the relationship and supported data acquisition and sharing activities. In contrast to the relational approach adopted by Rail B, Rail A did not rely much on relational governance mechanisms to support data gathering and sharing. For example, Rail A was afraid that if they were too transparent, they might provide too much information to their supplier (providing them with an advantage over other potential suppliers) and hence infringe on European tendering regulations. As such, Rail A rigidly enforced the contract and was unable to avert distrust. Consequently, the private supplier provided only the bare minimum in data (as per the contract), fearing that sharing too much data would be used against them by Rail A [47, 48].

Regarding transformation activities, Road's strategy to collaborate more closely with suppliers helped in building trust, which created transparency, and establishing collaborative relationships in which shared objectives could be identified. This motivated parties to engage in joint information transformation activities that helped limit the messiness of information and enabled the joint development of a dashboard to, for example, monitor the states of sluice doors with real-time information (Road B). Furthermore, both cases at Road focussed on the benefits that partners could obtain from relevant information and that simultaneously addressed their converging goals (e.g. more efficient maintenance for the supplier resulting in higher profits, more efficient asset management for Road resulting in a higher availability of the network) [16, 17, 35]. Creating such common objectives helped to motivate Road and their suppliers to transform data, both individually and jointly, thereby limiting the messiness of information. Rail, in contrast, relied heavily on internal resources for transformation activities, with limited opportunities for suppliers to engage with the public organisation in a joint transformation process. Rail A did not invest in building a trusting relationship with the supplier, since Rail A believed that any data transformation activities that the supplier could perform would only result in "fragmented, or even tainted, information". Table 5 shows, for example, that the supplier's management and their engineers had diverging ideas about performance [53]. While the supplier's engineers tried to perform as if they "owned" the assets that they were maintaining (i.e. more aligned with Rail A's interest to lower the number of failures and thus increase availability), their management more strictly followed the contract (i.e. performing enough maintenance to meet minimum contract requirements and maximise their profit). This led to differences in how both parties interpreted information regarding the supplier's performance and the assets' availability. Rail B invested in establishing relational norms (i.e. setting up a reference guide for their intended collaboration), with the intention of motivating the private supplier to go beyond the letter of the contract and to propose possible data transformation opportunities other than those prescribed in the contract [67]. This approach was described by both parties as creating more flexibility in the relationship, which was needed to address emerging issues and to consider the relationship a partnership (rather than a transactional relationship) involving both partners to maintain the rail network as effectively as possible as to increase network availability.

In sum, relational governance mechanisms were found to be less effective when addressing information uncertainty and to - at most - complement the required contractual governance mechanisms. Relational governance mechanisms (i.e. relational norms and trust) were effective in addressing information equivocality.

\section{Discussion}

Drawing on IPT, we posit that information uncertainty and equivocality in relationships undergoing DT are addressed by data gathering (and sharing) and transformation activities. Our investigation of four public-private relationships shows that both contractual and 
IJOPM

41,7 relational governance mechanisms can be used, but in different roles, to manage information asymmetry.

\subsection{Theoretical contributions}

This study contributes to inter-organisational governance and DT research. First, this study draws out how DT affects information uncertainty and equivocality. Digital technologies may reduce information uncertainty by enhancing both the quantity and quality of data available for decision-making (Sternberg et al., 2021). In the context of smart sensors, our findings show that they enable data to be collected in real time and that measurements tend to be more accurate. Advanced data analytics tools (Frank et al., 2019) enable combining data from different sources (e.g. SCADA and asset management systems, weather forecasts) and with expertise of relevant specialists (e.g. on asset utilisation, or the impact of weather conditions), thereby reducing equivocality. The findings, however, demonstrate that merely having these technological solutions in place does not guarantee enhanced information processing. Rather, challenges in data acquisition and transformation activities pertain to organisational aspects of implementing digital technologies and to the management of the IORs in which data from these technologies play a role. This is especially true for publicprivate relationships, which are characterised by different information processing needs. The public organisations in our study serve the public by providing safe, reliable and affordable transport to citizens and are held accountable by the national government in case of failures (e.g. low availability, accidents). As a result, these public organisations "need to know more than they buy" (Flowers, 2007) and hence require more information than suppliers would generally be inclined to provide (e.g. not only showing that a repair was made, but also that the failure did not impact safety). Based on our findings, we also show that public organisations and private suppliers differ in their main objectives (i.e. high availability vs maintenance volume) which, as shown in our case findings, caused both parties in the publicprivate relationship to make different decisions using the same information (e.g. postponing maintenance vs performing it now). We thus find that merely equipping assets with digital technologies does not yield any benefits if private suppliers fail to act upon the data these technologies generate and if data are not shared between partners. Thus, informationprocessing activities need to be properly organised (to ensure that both partners in the relationship contribute to the effective execution of the necessary processing activities) if public-private relationships are to reap the benefits that digital technologies can provide. Governance mechanisms can play a key role by explicating rules and operating procedures as well as by providing relationship-governing guidelines for data collection, sharing and transformation.

Second, this study theoretically and empirically contributes to inter-organisational governance literature by investigating the roles of contractual and relational governance mechanisms with regard to addressing information asymmetry in relationships undergoing DT. This is important because separate, yet interdependent, data collection and analysis activities increase organisations' strategic interdependence (Mahapatra et al., 2010) in successfully exploiting data-driven decision-making. As evidenced in our cases, effective deployment of both governance mechanisms helps to address information asymmetry. However, different governance mechanisms are needed depending on the nature of information asymmetry. More specifically, information gathering and sharing between partners can be explicated and stipulated using contracts' control and coordination functions geared at supporting collecting data and sharing it with the public organisation. To be useful for both parties in the relationship, these contractual control and coordination provisions need further detail and clarification regarding, for example, the format in which data should be collected and shared and the desired levels of detail. The contractually stipulated incentive 
schemes also need to be proportional (Selviaridis and Van der Valk, 2019) if data gathering and sharing are to achieve the desired levels. In other words, incentive schemes need to include both penalties and bonuses, and these are required at levels that incentivise suppliers to put effort into data gathering and sharing. Furthermore, organisations might benefit from more extensive use of coordination clauses aimed at establishing communication routines (e.g. frequency and detail of regular meetings) to exchange data and increase their understanding of each other's information requirements. Contractual mechanisms are found to be less prominent in data transformation activities. One plausible explanation seems to lie in the difficulty of defining information requirements in advance of DT with both parties struggling to define and bound precise specifications for data transformation. Also, when data acquisition and sharing are not properly organised via a contract's coordination clauses, information transformation between parties is limited. Data acquisition first needs to be properly organised, before organisations seek to organise transformation activities.

Our study finds that data acquisition and sharing mainly benefit from the use of relational governance such as trust and relational norms. Where trusting relationships are developed, suppliers are more open about the data they collected and engage more frequently in discussions regarding potential issues and new ideas with respect to using collected data to optimise their maintenance activities. Establishing collaboration and setting joint objectives aid partners in developing a clear perspective on what kind of data are required for what purpose. This may successfully be achieved by developing relational norms as these create a bilateral expectation (Cannon et al., 2000) that parties will proactively provide relevant (and often beyond contractually stipulated) information to their partner and thus support decisionmaking in the relationship. Furthermore, in the presence of trust, parties are more likely to spend time collecting and sharing data (Inkpen and Tsang, 2005). Trust also plays a vital role with respect to data transformation activities by increasing collaboration and information exchange between partners, and it helps them to share objectives with each other more freely. Increasing the level of trust between partnering organisations may help organisations to actively exchange relevant information and openly discuss collected data and possible interpretations. This may also support aligning interpretations between partnering organisations and thus lead to joint synthesis of information.

\subsection{Boundary conditions and further research}

In this study, the roles of governance mechanisms in addressing information asymmetry in public-private relationships during DT are closely examined. While our findings are relevant to public and private organisations beyond the investigated sectors and country, future research should compare our findings with other types of relationships (private-private or involving NGOs) and other sectors with different characteristics (e.g. different clock speed or types of products/services). This may have an impact on how information asymmetry is addressed. For instance, relationships in fast-moving product industries may not have the time to collect, analyse and transfer rich information and may rely on other means to address information asymmetry. In addition, the investigated public-private relationships are characterised by possible diverging goals and objectives (e.g. social vs economic value) which may lead to further information asymmetry and thus making them an ideal context for our study. Future research should investigate other types of relationships where goals and objectives might be more aligned (e.g. joint economic value creation and appropriation) and their impact on information asymmetry and the use of both governance mechanisms.

This study focusses on a particular type of digital technology. Other types of digital technologies, such as the use of blockchain technology to secure information transfers, should be investigated too to obtain a broader view of how different technologies affect information asymmetry. Moreover, investigating the findings in countries with different legal practices
Managing
information
asymmetry

1179 
IJOPM

41,7

1180

(i.e. different legal systems, importance of different contract types) may reveal the different roles both governance mechanisms play in addressing information asymmetry. Finally, this study leverages many sources of data including interviews, observations, contracts and archival data. Future studies may use behavioural experiments to uncover the role that different individuals play in using both governance mechanisms to address information asymmetry. For instance, further work should explore whom, at what level (e.g. business, corporate, subsidiary) and in what job role (e.g. legal, engineering, supply chain) uses what type of governance mechanism to gather, analyse and transfer information.

\subsection{Implications for practice}

This study has important implications for organisations and managers seeking to use governance mechanisms to address information asymmetry in relationships undergoing DT. Adopting and implementing digital technologies as such will not enhance informationprocessing capacity (as shown in the case where not enough staff was present to transform collected information) and capabilities (as specific expertise from the relationship partners needs to be combined), unless organisational and relationship management aspects associated with DT are properly dealt with. (Public) Organisations embarking on DT should therefore carefully consider how this would affect their relationships and their dealings with (private) partners, but also how processes, resources and structures may need to be adapted internally to deal with increased data and information. Our study provides valuable levers for the effective deployment of contractual and relational governance mechanisms in supporting information-processing activities and the management of information asymmetry in IORs.

In order to deploy both governance mechanisms effectively, organisations should first develop a thorough understanding of their own information requirements (including, but not limited to, questions around what, when, how, why and who) in relation to operational and contractual decision-making as well as the information requirements of partners. While information requirements may be clear in some areas, our study revealed that in most cases it is not. Public organisations may have difficulties identifying their essential information requirements. Organisations (and especially public ones) may lack crucial and specialised technical knowledge of the operational tasks of maintenance that they have outsourced to private suppliers. Additionally, public organisations typically work with tight budgets that do not allow simultaneous investments in current and new maintenance processes supported by digital technologies. Taken together, these issues inhibit organisations from developing a clear understanding of their information requirements. Increased collaboration with suppliers may foster such understanding, as suppliers are likely to be able to help establish and address information requirements based on their experiences with other customers and sectors. However, collaboration is problematic as public organisations and their private suppliers have diverging interests, leading public organisations to require higher quantities and quality of information than other (private) customers. Moreover, public organisations tend to refrain from too close collaborations with suppliers to avoid supplier lock-ins or the unintended creation of unfair competition between current and potential suppliers, thus making collaborative public-private relationships more difficult to achieve.

When information requirements are sufficiently clear, contracts should explicitly stipulate these information requirements and what data are required. Associated incentive schemes should be proportional and functional to be effective. Our research provides specific insights into how contractual and relational governance mechanisms help coordinate informationprocessing activities. Contracts help establish data gathering and transformation processes by facilitating communication and information transfer, thereby reducing the information uncertainty that the relationship faces. Relational mechanisms may strengthen this 
relationship as trust, openness and establishing common goals help to refine both parties' understanding of information requirements. Relational mechanisms play an even more important role in transformation activities as strong relationships help to develop the skills required for understanding the information held jointly. Joint problem-solving helps to develop the information structuring and evaluation skills of individual decision-makers in the relationship.

\section{Conclusion}

This paper explored how organisations in public-private relationships use contractual and relational governance mechanisms to organise information-processing activities in addressing information uncertainty and equivocality during DT. Information gathering and sharing activities can be made explicit and can be stipulated in contracts, which mainly serve to reduce information uncertainty. Information transformation activities are predominantly supported by relational mechanisms including trust, flexibility and joint problem-solving to address information equivocality. Our findings show that organisations need to first organise data acquisition and sharing activities before they can embark on organising data transformation activities (internally and with their partner). We are hopeful that these insights will encourage further research to refine our understanding of the roles of both governance mechanisms in addressing information asymmetry during DT.

\section{References}

Alvesson, M. (2003), "Beyond neopositivists, romantics, and localists: a reflexive approach to interviews in organizational research", Academy of Management Review, Vol. 28 No. 1, pp. 13-33.

Baldus, B.J. and Hatton, L. (2020), "US chief procurement officers' perspectives on public procurement”, Journal of Purchasing and Supply Management, Vol. 26 No. 1, pp. 1-17.

Barratt, M., Choi, T.Y. and Li, M. (2011), "Qualitative case studies in operations management: trends, research outcomes, and future research implications", Journal of Operations Management, Vol. 29 No. 4, pp. 329-342.

Blome, C., Schoenherr, T. and Kaesser, M. (2013), "Ambidextrous governance in supply chains: the impact on innovation and cost performance", Journal of Supply Chain Management, Vol. 49 No. 4, pp. 59-80.

Bode, C., Wagner, S.M., Petersen, K.J. and Ellram, L.M. (2011), "Understanding responses to supply chain disruptions: insights from information processing and resource dependence perspectives", Academy of Management Journal, Vol. 54 No. 4, pp. 833-856.

Bokrantz, J., Skoogh, A., Berlin, C. and Stahre, J. (2020), "Smart maintenance: instrument development, content validation and an empirical pilot", International Journal of Operations and Production Management, Vol. 40 No. 4, pp. 481-506.

Brinch, M. (2018), "Understanding the value of big data in supply chain management and its business processes: towards a conceptual framework", International Journal of Operations and Production Management, Vol. 38 No. 7, pp. 1589-1614.

Burns, L.R. and Wholey, D.R. (1993), "Adoption and abandonment of matrix management programs: effects of organizational characteristics and interorganizational networks", Academy of Management Journal, Vol. 36 No. 1, pp. 106-138.

Cabral, S. (2017), "Reconciling conflicting policy objectives in public contracting: the enabling role of capabilities", Journal of Management Studies, Vol. 54 No. 6, pp. 823-853.

Cabral, S., Mahoney, J.T., McGahan, A.M. and Potoski, M. (2019), "Value creation and value appropriation in public and nonprofit organizations", Strategic Management Journal, Vol. 40 No. 4, pp. 465-475. 
IJOPM

41,7

Caldwell, N.D., Roehrich, J.K. and Davies, A.C. (2009), "Procuring complex performance in construction: London Heathrow Terminal 5 and a private finance initiative hospital", Journal of Purchasing and Supply Management, Vol. 15 No. 3, pp. 178-186.

Caldwell, N.D., Roehrich, J.K. and George, G. (2017), "Social value creation and relational coordination in public-private collaborations", Journal of Management Studies, Vol. 54 No. 6, pp. 906-928.

Cannon, J.P., Achrol, R.S. and Gundlach, G.T. (2000), "Contracts, norms, and plural form governance”, Journal of the Academy of Marketing Science, Vol. 28 No. 2, pp. 180-194.

Cao, Z. and Lumineau, F. (2015), "Revisiting the interplay between contractual and relational governance: a qualitative and meta-analytic investigation”, Journal of Operations Management, Vols 33-34 No. 1, pp. 15-42.

Carey, S., Lawson, B. and Krause, D.R. (2011), "Social capital configuration, legal bonds and performance in buyer-supplier relationships", Journal of Operations Management, Vol. 29 No. 4, pp. 277-288.

Carson, S.J. and John, G. (2013), "A theoretical and empirical investigation of property rights sharing in outsourced research, development, and engineering relationships", Strategic Management Journal, Vol. 34 No. 9, pp. 1065-1085.

Chakkol, M., Selviaridis, K. and Finne, M. (2018), "The governance of collaboration in complex projects", International Journal of Operations and Production Management, Vol. 38 No. 4, pp. 997-1019.

Daft, R.L. and Lengel, R.H. (1986), "Organizational information requirements, media richness and structural design”, Management Science, Vol. 32 No. 5, pp. 554-571.

Daft, R.L. and Weick, K.E. (1984), "Toward a model of organizations as interpretation systems", Academy of Management Review, Vol. 9 No. 2, pp. 284-295.

Dahlmann, F. and Roehrich, J.K. (2019), "Sustainable supply chain management and partner engagement to manage climate change information", Business Strategy Environment, Vol. 28 No. 8, pp. 1632-1647.

Ellram, L.M. (1996), "The use of the case study method in logistics research", Journal of Business Logistics, Vol. 17 No. 2, pp. 93-138.

Ellram, L.M., Tate, W.L. and Choi, T.Y. (2020), "The conflicted role of purchasing in new product development costing", Journal of Supply Chain Management, Vol. 56 No. 1, pp. 3-32.

EPEC (2017), European PPP Expertise Centre's (EPEC) Data Portal, European Investment Bank, available at: https://data.eib.org/epec (accessed 7 March 2021).

Essig, M., Glas, A.H., Selviaridis, K. and Roehrich, J.K. (2016), "Performance-based contracting in business markets", Industrial Marketing Management, Vol. 59, pp. 5-11.

Faems, D., Janssens, M., Madhok, A. and Van Looy, B. (2008), "Toward an integrative perspective on alliance governance: connecting contract design, trust dynamics, and contract application”, Academy of Management Journal, Vol. 51 No. 6, pp. 1053-1078.

Fiol, C.M. (1994), "Consensus, diversity, and learning in organizations", Organization Science, Vol. 5 No. 3, pp. 403-420.

Flowers, S. (2007), "Organizational capabilities and technology acquisition: why firms know less than they buy", Industrial and Corporate Change, Vol. 16 No. 3, pp. 317-346.

Formentini, M. and Taticchi, P. (2016), "Corporate sustainability approaches and governance mechanisms in sustainable supply chain management”, Journal of Cleaner Production, Vol. 112, pp. 1920-1933.

Frank, A.G., Dalenogare, L.S. and Ayala, N.F. (2019), "Industry 4.0 technologies: implementation patterns in manufacturing companies", International Journal of Production Economics, Vol. 210, pp. 15-26.

Galbraith, J.R. (1973), Designing Complex Organizations, Addison-Wesley Longman Publishing, Reading, MA.

Galbraith, J.R. (1974), “Organization design: an information processing view”, Interfaces, Vol. 4 No. 3, pp. 28-36. 
Gattiker, T.F. and Goodhue, D.L. (2004), "Understanding the local-level costs and benefits of ERP through organizational information processing theory", Information and Management, Vol. 41 No. 4, pp. 431-443.

Ghosh, A. and Fedorowicz, J. (2008), "The role of trust in supply chain governance", Business Process Management Journal, Vol. 14 No. 4, pp. 453-470.

Gibbert, M., Ruigrok, W. and Wicki, B. (2008), "What passes as a rigorous case study?", Strategic Management Journal, Vol. 29 No. 13, pp. 1465-1474.

Glock, C.H., Grosse, E.H. and Ries, J.M. (2017), "Reprint of 'Decision support models for supplier development: systematic literature review and research agenda", International Journal of Production Economics, Vol. 194, pp. 246-260.

Golden-Biddle, K. and Locke, K. (2007), Composing Qualitative Research, 2nd ed., SAGE Publications, Thousand Oaks, CA.

Gulati, R., Wohlgezogen, F. and Zhelyazkov, P. (2012), "The two facets of collaboration: cooperation and coordination in strategic alliances", Academy of Management Annals, Vol. 6 No. 1, pp. 531-583.

Halldórsson, Á. and Skjøtt-Larsen, T. (2006), "Dynamics of relationship governance in TPL arrangements - a dyadic perspective", International Journal of Physical Distribution and Logistics Management, Vol. 36 No. 7, pp. 490-506.

Hart, O. (2003), "Incomplete contracts and public ownership: remarks, and an application to publicprivate partnerships", The Economic Journal, Vol. 113 No. 486, pp. 69-76.

Hartmann, A., Roehrich, J., Frederiksen, L. and Davies, A. (2014), "Procuring complex performance: the transition process in public infrastructure", International Journal of Operations and Production Management, Vol. 34 No. 2, pp. 174-194.

Hartmann, P.M., Zaki, M., Feldmann, N. and Neely, A. (2016), "Capturing value from big data - a taxonomy of data-driven business models used by start-up firms", International Journal of Operations and Production Management, Vol. 36 No. 10, pp. 1382-1406.

Heide, J.B. and John, G. (1992), "Do norms matter in marketing relationships?", Journal of Marketing, Vol. 56 No. 2, pp. 32-44.

Howard, M., Roehrich, J.K., Lewis, M.A. and Squire, B. (2019), "Converging and diverging governance mechanisms: the role of (dys)function in long-term inter-organisational relationships", British Journal of Management, Vol. 30 No. 3, pp. 624-644.

Huang, F., Chen, J., Sun, L., Zhang, Y. and Yao, S. (2020), "Value-based contract for smart operation and maintenance service based on equitable entropy", International Journal of Production Research, Vol. 58 No. 4, pp. 1271-1284.

Inkpen, A.C. and Tsang, E.W.K. (2005), "Social capital, networks, and knowledge transfer", Academy of Management Review, Vol. 30 No. 1, pp. 146-165.

Jayaraman, V., Narayanan, S., Luo, Y. and Swaminathan, J.M. (2013), "Offshoring business process services and governance control mechanisms: an examination of service providers from India", Production and Operations Management, Vol. 22 No. 2, pp. 314-334.

Jick, T.D. (1979), "Mixing qualitative and quantitative methods: triangulation in action", Administrative Science Quarterly, Vol. 24 No. 4, pp. 602-611.

Kache, F. and Seuring, S. (2017), "Challenges and opportunities of digital information at the intersection of big data analytics and supply chain management", International Journal of Operations and Production Management, Vol. 37 No. 1, pp. 10-36.

Kalra, J., Lewis, M. and Roehrich, J.K. (2021), "The manifestation of coordination failures in service triads", Supply Chain Management: An International Journal, Vol. 26 No. 3, pp. 341-358.

Kapsali, M., Roehrich, J.K. and Akhtar, P. (2019), "Effective contracting for high operational performance in projects", International Journal of Operations and Production Management, Vol. 39 No. 2, pp. 294-325. 
IJOPM

41,7

1184

Kivleniece, I. and Quelin, B.V. (2012), "Creating and capturing value in public-private ties: a private actor's perspective", Academy of Management Review, Vol. 37 No. 2, pp. 272-299.

Klein, P.G., Mahoney, J.T., McGahan, A.M. and Pitelis, C.N. (2010), "Toward a theory of public entrepreneurship", European Management Review, Vol. 7 No. 1, pp. 1-15.

Klein, P.G., Mahoney, J.T., McGahan, A.M. and Pitelis, C.N. (2019), "Organizational governance adaptation: who is in, who is out, and who gets what", Academy of Management Review, Vol. 44 No. 1, pp. 6-27.

Kreye, M.E., Roehrich, J.K. and Lewis, M.A. (2015), "Servitising manufacturers: the impact of service complexity and contractual and relational capabilities", Production Planning and Control, Vol. 26 Nos 14-15, pp. 1233-1246.

Lanzolla, G., Lorenz, A., Miron-Spektor, E., Schilling, M., Solinas, G. and Tucci, C. (2018), "Digital transformation: what is new if anything?", Academy of Management Discoveries, Vol. 4 No. 3, pp. 378-387.

Lepak, D.P., Smith, K.G. and Taylor, M.S. (2007), "Value creation and value capture: a multilevel perspective”, Academy of Management Review, Vol. 32 No. 1, pp. 180-194.

Lumineau, F. (2017), "How contracts influence trust and distrust", Journal of Management, Vol. 43 No. 5, pp. 1553-1577.

Luo, Y. (2002), "Contract, cooperation, and performance in international joint ventures", Strategic Management Journal, Vol. 23 No. 10, pp. 903-919.

Mahapatra, S.K., Narasimhan, R. and Barbieri, P. (2010), "Strategic interdependence, governance effectiveness and supplier performance: a dyadic case study investigation and theory development", Journal of Operations Management, Vol. 28 No. 6, pp. 537-552.

Mahoney, J.T., McGahan, A.M. and Pitelis, C.N. (2009), "The interdependence of private and public interests", Organization Science, Vol. 20 No. 6, pp. 1034-1052.

Mayer, K.J. and Argyres, N.S. (2004), "Learning to contract: evidence from the personal computer industry”, Organization Science, Vol. 15 No. 4, pp. 394-410.

McCutcheon, D.M. and Meredith, J.R. (1993), "Conducting case study research in operations management”, Journal of Operations Management, Vol. 11 No. 3, pp. 239-256.

Mesquita, L.F. and Brush, T.H. (2008), "Untangling safeguard and production coordination effects in long-term buyer-supplier relationships", Academy of Management Journal, Vol. 51 No. 4, pp. $785-807$.

Miles, M.B. and Huberman, A.M. (1994), Qualitative Data Analysis: An Expanded Sourcebook, 2nd ed., SAGE Publications, Thousand Oaks, CA.

Mishra, A. and Browning, T.R. (2020), "Editorial: the innovation and project management department in the Journal of Operations Management", Journal of Operations Management, Vol. 66 No. 6, pp. 616-621.

Olsen, T.L. and Tomlin, B. (2020), "Industry 4.0: opportunities and challenges for operations management", Manufacturing and Service Operations Management, Vol. 22 No. 1, pp. 113-122.

Olsen, B.E., Haugland, S.A., Karlsen, E. and Johan Husøy, G. (2005), "Governance of complex procurements in the oil and gas industry", Journal of Purchasing and Supply Management, Vol. 11 No. 1, pp. 1-13.

Patton, M.Q. (1990), Qualitative Evaluation and Research Methods, 2nd ed., SAGE Publications, Thousand Oaks, CA.

Poppo, L. and Zenger, T. (2002), "Do formal contracts and relational governance function as substitutes or complements?”, Strategic Management Journal, Vol. 23 No. 8, pp. 707-725.

Poppo, L., Zhou, K.Z. and Ryu, S. (2008), "Alternative origins to interorganizational trust: an interdependence perspective on the shadow of the past and the shadow of the future", Organization Science, Vol. 19 No. 1, pp. 39-55. 
Puranam, P., Singh, H. and Zollo, M. (2006), "Organizing for innovation: managing the coordinationautonomy dilemma in technology acquisitions", Academy of Management Journal, Vol. 49 No. 2, pp. 263-280.

Quelin, B.V., Kivleniece, I. and Lazzarini, S. (2017), "Public-private collaboration, hybridity and social value: towards new theoretical perspectives", Journal of Management Studies, Vol. 54 No. 6, pp. 763-792.

Quelin, B.V., Cabral, S., Lazzarini, S. and Kivleniece, I. (2019), "The private scope in public-private collaborations: an institutional and capability-based perspective", Organization Science, Vol. 30 No. 4, pp. 831-846.

RAE (2012), Smart Infrastructure: The Future, The Royal Academy of Engineering, London, available at: www.raeng.org.uk/smartinfrastructure.

Rangan, S., Samii, R. and Van Wassenhove, L.N. (2006), "Constructive partnerships: when alliances between private firms and public actors can enable creative strategies", Academy of Management Review, Vol. 31 No. 3, pp. 738-751.

Roehrich, J.K. and Kivleniece, I. (2021), "Creating and distributing sustainable value through publicprivate collaborative projects", in George, G., Hass, M.R., Joshi, H., McGahan, A. and Tracey, P. (Eds), Handbook on the Business of Sustainability: The Organization, Implementation, and Practice of Sustainable Growth, Edward Elgar Publishing, Cheltenham, Forthcoming, pp. 1-53.

Roehrich, J.K. and Lewis, M.A. (2014), "Procuring complex performance: implications for exchange governance complexity", International Journal of Operations and Production Management, Vol. 34 No. 2, pp. 221-241.

Roehrich, J.K., Lewis, M.A. and George, G. (2014), "Are public-private partnerships a healthy option? A systematic literature review”, Social Science and Medicine, Vol. 113, pp. 110-119.

Roehrich, J.K., Selviaridis, K., Kalra, J., Van der Valk, W. and Fang, F. (2020), "Inter-organizational governance: a review, conceptualisation and extension", Production Planning and Control, Vol. 31 No. 6, pp. 453-469.

Roehrich, J.K., Tyler, B.B., Kalra, J. and Squire, B. (2021), "The decision process of contracting in supply chain management", in Choi, T.Y., Li, J.J., Rogers, D.S., Rungtusanatham, J., Schoenherr, T. and Wagner, S.M. (Eds), Handbook of 'Supply Chain Management', Oxford University Press, Oxford.

Rosado Feger, A.L. (2014), "Creating cross-functional strategic consensus in manufacturing facilities", International Journal of Operations and Production Management, Vol. 34 No. 7, pp. 941-970.

Schepker, D.J., Oh, W.Y., Martynov, A. and Poppo, L. (2014), "The many futures of contracts: moving beyond structure and safeguarding to coordination and adaption", Journal of Management, Vol. 40 No. 1, pp. 193-225.

Schilke, O. and Lumineau, F. (2018), "The double-edged effect of contracts on alliance performance", Journal of Management, Vol. 44 No. 7, pp. 2827-2858.

Scurati, G.W., Gattullo, M., Fiorentino, M., Ferrise, F., Bordegoni, M. and Uva, A.E. (2018), "Converting maintenance actions into standard symbols for augmented reality applications in Industry 4.0", Computers in Industry, Vol. 98, pp. 68-79.

Selviaridis, K. (2016), "Contract functions in service exchange governance: evidence from logistics outsourcing", Production Planning and Control, Vol. 27 No. 16, pp. 1373-1388.

Selviaridis, K. and Van der Valk, W. (2019), "Framing contractual performance incentives: effects on supplier behaviour", International Journal of Operations and Production Management, Vol. 39 No. 2, pp. 190-213.

Shah, S.K. and Corley, K.G. (2006), "Building better theory by bridging the quantitative-qualitative divide*”, Journal of Management Studies, Vol. 43 No. 8, pp. 1821-1835.

Sivarajah, U., Kamal, M.M., Irani, Z. and Weerakkody, V. (2017), "Critical analysis of big data challenges and analytical methods", Journal of Business Research, Vol. 70, pp. 263-286. 
IJOPM 41,7

Steinbach, T., Wallenburg, C.M. and Selviaridis, K. (2018), "Me, myself and I: non-collaborative customer behavior in service outsourcing - the key role of outcome orientation and outcome attributability", International Journal of Operations and Production Management, Vol. 38 No. 7, pp. 1519-1539.

Sternberg, H.S., Hofmann, E. and Roeck, D. (2021), “The struggle is real: insights from a supply chain blockchain case", Journal of Business Logistics, Vol. 42 No. 1, pp. 71-87.

Thompson, J.D. (1967), Organizations in Action: Social Science Bases of Administration Theory, McGraw Hill, New York, NY.

Tushman, M.L. and Nadler, D.A. (1978), "Information processing as an integrating concept in organization design", Academy of Management Review, Vol. 3 No. 3, pp. 613-624.

Venkatraman, N. (1991), "IT-induced business reconfiguration", in Morton, M.S.S. (Ed.), The Corporation of the 1990s: Information Technology and Organizational Transformation, Oxford University Press, New York, NY, pp. 122-158.

Waller, M.A. and Fawcett, S.E. (2013), "Data science, predictive analytics, and big data: a revolution that will transform supply chain design and management", Journal of Business Logistics, Vol. 34 No. 2, pp. 77-84.

Weber, L. and Mayer, K.J. (2011), "Designing effective contracts: exploring the influence of framing and expectations", Academy of Management Review, Vol. 36 No. 1, pp. 53-75.

Wiengarten, F., Ahmed, M.U., Longoni, A., Pagell, M. and Fynes, B. (2017), "Complexity and the triple bottom line: an information-processing perspective", International Journal of Operations and Production Management, Vol. 37 No. 9, pp. 1142-1163.

Yin, R.K. (2009), Case Study Research: Design and Methods, 4th ed., SAGE Publications, Thousand Oaks, CA.

Yu, W., Chavez, R., Jacobs, M., Wong, C.Y. and Yuan, C. (2019), "Environmental scanning, supply chain integration, responsiveness, and operational performance: an integrative framework from an organizational information processing theory perspective", International Journal of Operations and Production Management, Vol. 39 No. 5, pp. 787-814.

Zhao, Y., Feng, T. and Shi, H. (2018), "External involvement and green product innovation: the moderating role of environmental uncertainty”, Business Strategy Environment, Vol. 27 No. 8, pp. 1167-1180.

Zheng, J., Roehrich, J.K. and Lewis, M.A. (2008), "The dynamics of contractual and relational governance: evidence from long-term public-private procurement arrangements", Journal of Purchasing and Supply Management, Vol. 14 No. 1, pp. 43-54. 


\section{Appendix 1}

The interview protocol below lists the generic and function-specific questions that guided the semistructured interviews.

General Questions (all interviewees)

(1) Can you describe the total value (economically, socially, etc.) of the assets for which your organisation is responsible?

(2) To what extent are data and information already utilised when performing management and maintenance activities?

Management and Maintenance Activities (Asset Managers and Asset Specialists).

(1) Can you describe how the management and maintenance activities of the infrastructure assets are currently organised?

(2) To what extent is your organisation ready for smarter maintenance methods?

(3) Are there any steps left to be taken by your organisation to achieve smart management and maintenance of assets? If so, can you describe these steps?

(4) Can you describe which role suppliers should play in realising smarter maintenance methods? Manager)

(1) What data does your organisation (plan to) share with supplier(s) and what data does your organisation (plan to) request from supplier(s)?

(2) To what extent does your organisation request supplier(s) to contribute to the implementation of digital technologies for the purpose of maintenance?

(3) In your opinion, what role will data and information play regarding smarter maintenance?

(4) Which party do you think should take a leading role in achieving smarter maintenance?

Outsourcing of Maintenance (Advisor, Regional Director and Contract Managers)

(1) Can you describe the design/ structure of the maintenance contract?

(2) Can you describe the outsourcing process for maintenance activities?

(3) Can you describe the last maintenance contract awarded by your department?

(4) Can you describe the collaboration with the current supplier?

(5) Can you describe what a future cooperation should look like? 
IJOPM

41,7

\section{8}

\section{Appendix 2}

The table below summarises the different tactics and their operationalisation within our study to enhance reliability and validity.

\begin{tabular}{|c|c|c|}
\hline Test & Tactic & Research Stage \\
\hline $\begin{array}{l}\text { Construct } \\
\text { Validity }\end{array}$ & $\begin{array}{l}\text { Using multiple sources of } \\
\text { evidence to enable } \\
\text { triangulation of data }\end{array}$ & $\begin{array}{l}\text { Exploratory st } \\
\text { In-depth case } \\
\text { stage }\end{array}$ \\
\hline
\end{tabular}

Establishing a clear chain of evidence

In-depth case research stage

Letting key informants review draft reports

(Internal and External) Validity

Reliability

Interview protocol

Case study database

Table A1. Summary of research credibility
Using replication logic in
multiple case studies (pattern matching)
In-depth case research stage

In-depth case research stage

Exploratory stage and In-depth case research stage

Exploratory stage and In-depth case research stage
Source(s): Adapted from Gibbert et al. (2008), Yin (2009)
Operationalisation

(1) Evidence was collected from multiple groups of informants at buyer side (e.g. data specialists, maintenance experts and contract managers) regarding both the buyer side as well as supplier side

(2) Gained access to contract documents governing the relationships under investigation

(3) Additional documentary evidence (e.g. firm documents and government reports) and observational notes were collected to support data triangulation

(1) Detailed case study descriptions written, based on all sources of evidence, to uncover information processing activities and governance mechanisms used in investigated relationships

(2) Original material (e.g. interview transcripts and documentary evidence) is referenced throughout the paper

(1) Case study descriptions were discussed during extensive meetings that included both the two lead authors as well as a small selection of key informants from both case organisations to verify our analyses

(2) Informal talks by the lead author with a selection of key informants to clarify interview transcripts

(1) Analysis of case studies was guided by several main concepts that were derived from existing literature (IPT and governance mechanisms)

(2) Built on "analytical generalisation" by seeking to identify patterns across the four case

(3) Case studies aimed to generalise to some wider theory (i.e.IPT), rather than to a population

(1) Interview protocols were established based on concepts from existing literature and they contained the procedures and questions for data collection during both research stages

(1) We created a case study database in Atlas.ti and Windows File Explorer while collecting data including, for instance interview transcripts, observational notes and contract documents 
Appendix 3

The figure below presents the final coding structure that was constructed for the data analysis.

- Types of data generated.

- Determining the specific data

that is needed.

- Degree to which IT-system

can cope with demands.

- How data can be accessed by

both parties collectively.

- Establishing a connection to

automatically share data.

- Data ownership.

- Types of data shared

between both parties.

- Importance of shared data to

both parties.

- How the data is administrated

by the collecting party.

- Time interval at which data is

being shared.

- The extent to which both parties share data.

- How both parties perceive the quality of the shared

data.

- How data is analysed and

used by both parties.

- The extent to which data is

complete.

- Organisation of data

transformation activities at both parties.

- Too much data to handle.

- Limited budget to implement

new technologies.

- Current knowledge levels at

both organisations with

respect to data analytics.

- Attendance during recurring

joint meetings.

- Other communication

between public organisation and supplier.

- Behaviour of the supplier with respect to the public organisation.

- How the supplier perceives

the image of the public

organisation.

- Degree of freedom given to

supplier to determine how the

achieve contractual goals.

- General trust (e.g.

transparency and open communication).

- Efforts made by supplier to improve relationship.

- Willingness to go the extra

mile by supplier.

- Degree to which both parties

are focused on cooperation.

- Dependence supplier on

public organisation.

- Dependence public

organisation on supplier.

Figure A1.

Final coding scheme 


\section{IJOPM 41,7}

\section{0}

Figure A1.

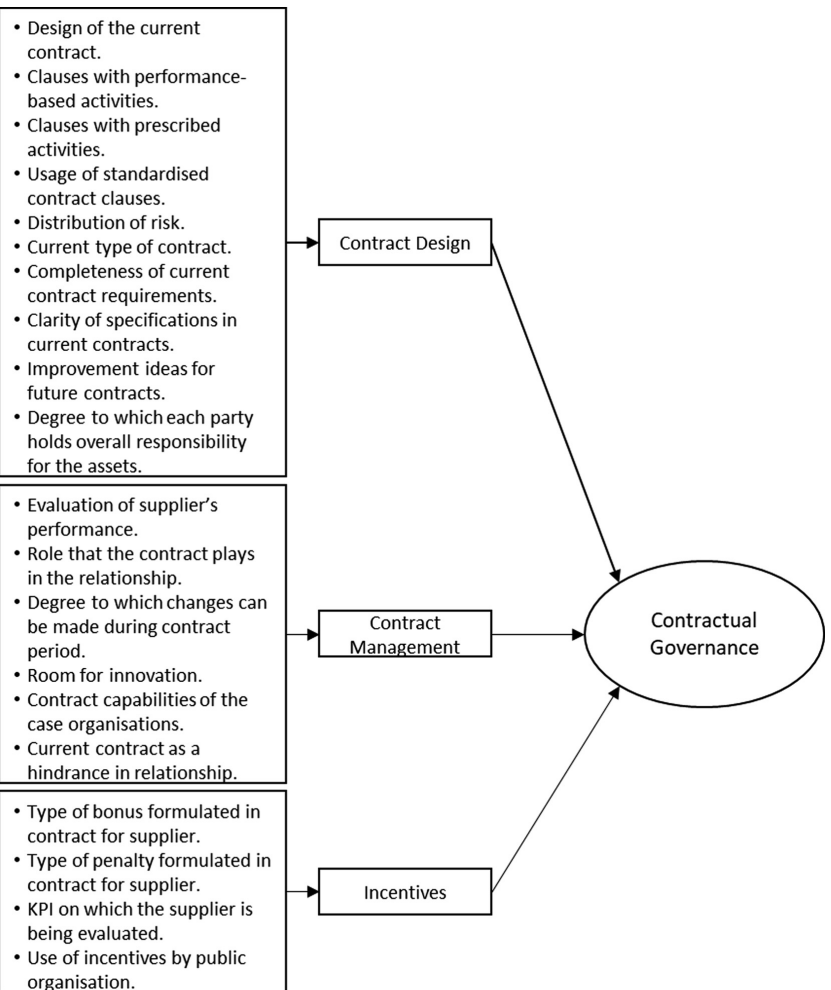

contract.

based activities.

- Clauses with prescribed

Usage of standardise

- Current type of contract.

Completeness of current

contract requirements.

current contracts.

party

Evaluation of supplier's

performance.

Degree to which changes can

- Room for innovation.

Contract capabilities of the

Type of bonus formulated in

contract for supplier.

- Type of penalty formulated in

being evaluated.

organisation

\section{About the authors}

Tom A.E. Aben is a PhD candidate at Tilburg University, the Netherlands. He earned his M.Sc. in Supply Chain Management at Tilburg University. His research focusses on the impact of digital technologies on inter-organisational relationships and specifically public-private relationships and the influence of (big) data on contractual and relational governance mechanisms utilised in inter-organisational relationships. Tom A.E. Aben is the corresponding author and can be contacted at: t.a.e.aben@tilburguniversity.edu

Professor Wendy van der Valk is the Nevi Chair in Purchasing and Supply Chain Management at Tilburg University, the Netherlands. Her research focusses on the effective governance of interorganisational relationships, specifically the contracting of business-critical services, in relation to contemporary transitions in business and society, such as digital transformation and circularity. She has published in journals such as International Journal of Operations and Production Management, Journal of Purchasing and Supply Management, Journal of Supply Chain Management, and Industrial Marketing Management.

Professor Jens K. Roehrich is the HPC Chair in Supply Chain Innovation at the University of Bath, School of Management, UK. Before joining Bath, Jens was a researcher at Imperial College London, UK. Significant strands of his research agenda explore, for instance, the long-term interplay of contractual and relational governance mechanisms in inter-organisational relationships and complex projects as well as the management of public-private relationships. His research has been published in journals such as Journal of Management Studies, International Journal of Operations and Production Management, British Journal of Management, Social Science and Medicine and Industrial Marketing Management, among others. 
Dr Kostas Selviaridis is an Associate Professor of Operations Management at Lancaster University Management School, UK. His research concerns the governance of inter-organisational relationships in supply chains, with an emphasis on the role of contracting. His current work explores, among other topics, how contracting can stimulate innovation in the delivery of public services (e.g. healthcare) and how procurement policies can align incentives in pharmaceutical supply chains to reduce drug shortages. Kostas' work has appeared in international outlets such as the International Journal of Operations and Production Management, Journal of Purchasing and Supply Management and Industrial Marketing Management, among others.

\section{Managing information asymmetry}

For instructions on how to order reprints of this article, please visit our website: 